\title{
UNA PROPUESTA DE CARACTERIZACIÓN DE LAS LLAMADAS REGIAE IBÉRICAS. COMERCIO, RELIGIÓN Y CONTROL TERRITORIAL A PARTIR DE UN MODELO ARQUITECTÓNICO
}

\author{
AN INTERPRETATION OF THE IBERIAN REGIAE. TRADE, RELIGION AND TERRITORIAL CONTROL \\ BASED ON AN ARCHITECTURAL MODEL
}

FERNANDO PRADOS MARTÍNEZ

Universidad de Alicante

\section{INTRODUCCIÓN. BREVE APROXIMACIÓN HISTORIOGRÁFICA}

Los santuarios, templos $\mathrm{y}$, en general, los llamados «espacios singulares» ibéricos han sido objeto de estudio de una forma sistemática sobre todo en las últimas décadas ${ }^{1}$. No vamos a entrar con detalle en este apartado historiográfico ya que no es el objeto del presente trabajo y lo prolongaría en exceso. Además, sobre estas cuestiones se han publicado diversos trabajos de interés que recogen de manera crítico-interpretativa los estudios y las principales hipótesis y teorías que se han ido generando con el avance de la investigación (entre otros Lucas, 1981; Gusi, 1997; Oliver, 1997; Vilà, 1997; Almagro y Moneo, 2000; Moneo, 2003). La cantidad de bibliografía es ingente sobre estos aspectos, por lo que nos ocuparemos de analizar muy sucintamente los trabajos que se han aproximado en detalle al tema de las llamadas «regiae» ibéricas, es decir, los espacios construidos, generalmente tripartitos, que presentan unas características particulares desde el punto de vista arquitectónico -tipológico- y que ofrecen un registro material susceptible de ser estudiado con detalle e interés para su identificación.

Este modelo arquitectónico que presentamos en estas páginas fue definido en origen como templo, fundamentalmente por el tipo de planta que presentaba, muy bien definida, de carácter complejo y monumental, y por haber sido documentado, hasta ese momento, siempre en contextos urbanos. La cuestión del emplazamiento «intramuros» de este tipo de construcciones provocó su natural identificación como templos urbanos (Lucas, 1981; Llobregat, 1983 y 1985; Prados Torreira, 1994; Bonet y Mata, 1997; Gusi, 1997; Moneo, 2003). Otras ocasiones fueron definidos de una forma

\footnotetext{
1. Queremos agradecer las aportaciones y sugerencias de los informantes anónimos, que han sido debidamente tenidas en cuenta y de gran utilidad a la hora de aproximarnos a este complejo tema.
}

menos concreta como «lugares de culto urbanos» (Oliver, 1997) y también como «santuarios empóricos» (Domínguez Monedero, 1997, 96), siempre en el marco del ámbito urbano.

El primer trabajo que traslada el empleo del concepto de regia o residencia palaciega a algunos modelos arquitectónicos ibéricos es el de Almagro-Gorbea y Domínguez de la Concha (Almagro y Domínguez, 1988-1989), que estudia el llamado palacio-santuario de Cancho Roano (Zalamea de la Serena, Badajoz) poniéndolo en relación con un amplísimo elenco de modelos palaciales próximo-orientales y mediterráneos (Fig. 1). Más recientemente, esta misma denominación ha sido empleada por T. Moneo para este tipo de construcciones en su obra de síntesis sobre santuarios ibéricos (Moneo, 2003). En los últimos años, el hallazgo de la llamada regia de las Tres Hermanas de Aspe $^{2}$ (Alicante) ha hecho retomar el uso del término y su interpretación (García y Moratalla, 1999; 1998-1999; Moratalla, 2005). Por último, en un reciente trabajo de M. Olcina que se ocupa nuevamente de los llamados templos A y B de la Illeta dels Banyets de El Campello (Alicante), se plantea de nuevo la identificación de santuario para este tipo de espacios -en concreto el templo A- desechando el uso del término regia al no ver en él aspectos definitorios que lo vinculen con una residencia palaciega (Olcina, 2005). La reciente publicación de una monografía que recoge la historia de las investigaciones y la síntesis de las más recientes intervenciones efectuadas sobre este fundamental yacimiento dan nueva luz en este sentido, reproduciendo los comentarios y anotaciones realizados por E. Llobregat en sus informes y diarios de excavación (Olcina, Martínez y Sala, 2009, concretamente entre

2. Ubicado a unos $2700 \mathrm{~m}$ al sur de la localidad, en la falda oriental de la central de las tres elevaciones conocidas como «Tres Hermanas» a unos 327 m s.n.m. (García y Moratalla, 2001). 


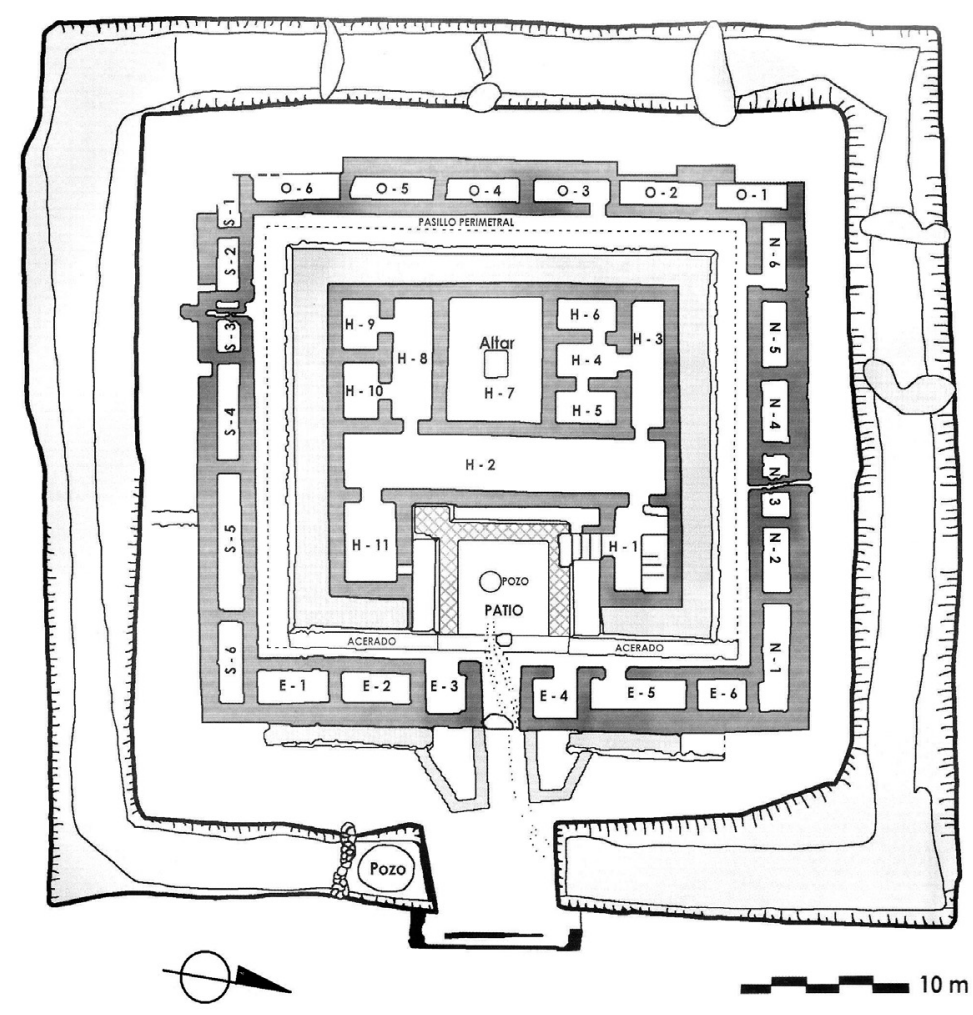

Figura 1: Planta completa del palacio-santuario de Cancho Roano (Zalamea de la Serena, Badajoz) según Celestino, 2001.

las páginas 110-115 los que aluden al proceso de excavación del «templo A»).

Buena parte de la bibliografía que se puede revisar sobre este modelo arquitectónico deriva de la búsqueda de paralelos, función y significado del edificio de Cancho Roano (Celestino, 1997, 360) y, en menor medida, de los templos de la Illeta de El Campello. Cancho Roano fue definido ya en los primeros trabajos que vieron la luz como «palacio-santuario», si bien en las sucesivas memorias de excavación publicadas fue denominado como santuario directamente, aunque siempre se subrayó el carácter palacial del edificio (Maluquer, 1981; 1983). Almagro-Gorbea ha incidido también en el carácter religioso del espacio, definiéndolo como palacio sacro o santuario palacial (Almagro-Gorbea, 1996), incluso palacio fortificado en otros trabajos recientes en colaboración (Almagro, Mederos y Torres, 2008, 161) o palacio-fortín, categoría en la que incluye también al cercano edificio pacense de La Mata de Campanario (Almagro y Torres, 2007, 46; 2009). Almagro no pone en duda nunca el origen oriental de este modelo y sitúa el arranque de este tipo de construcciones en el área sirio-palestina (Almagro-Gorbea et alii, 1990, 285). La comparación con los palacios orientales es problemática, sobre todo porque los modelos levantinos mencionados son de un tamaño mucho mayor (Celestino, 1997, 361). Para nuestro objeto de análisis nos interesan, fundamentalmente, los edificios más antiguos de Cancho Roano, definidos como edificios $\mathrm{B}$ y $\mathrm{C}$, donde, además de la estructura arquitectónica tripartita como las que estamos analizando en estas líneas, destaca la orientación este-oeste del complejo, junto con su modulación y dimensiones. De hecho, la práctica totalidad de los edificios que analizamos en este trabajo comparten una misma orientación solar, como tendrá ocasión de comprobar el lector.

Sobre la llamada regia de El Campello (Fig. 2 y Fig. 17), existió desde un principio discrepancia en lo concerniente a su lectura arquitectónica. En principio, se entendió la estructura del templo A como de tipo itálico, por su planta rectangular alargada (Llobregat, 1983; 1985). La vinculación de las estructuras exageradamente alargadas con los modelos itálicos está hoy sujeta a revisión, ya que el mundo púnico, mucho más próximo culturalmente a las regiones donde se generaron estos modelos (con algunos ejemplos hispanos de gran trascendencia, como el santuario de la Encarnación en Murcia, el santuario de Torrebenzalá, La Bobadilla o Torreparedones en Jaén-Córdoba o el templo del Cerro de los Santos en la provincia de Albacete), ofrece abundantes ejemplos de este tipo de planta que se deberían tener en cuenta (Pensabene, 1989). Igualmente, para M. Bendala, estas estructuras rectangulares alargadas son mucho más propias de ambientes punicizantes que estrictamente itálicos, lo que le ha llevado a dudar, por ejemplo, de la interpretación como capitolio del templo B de la ciudad hispanorromana de 


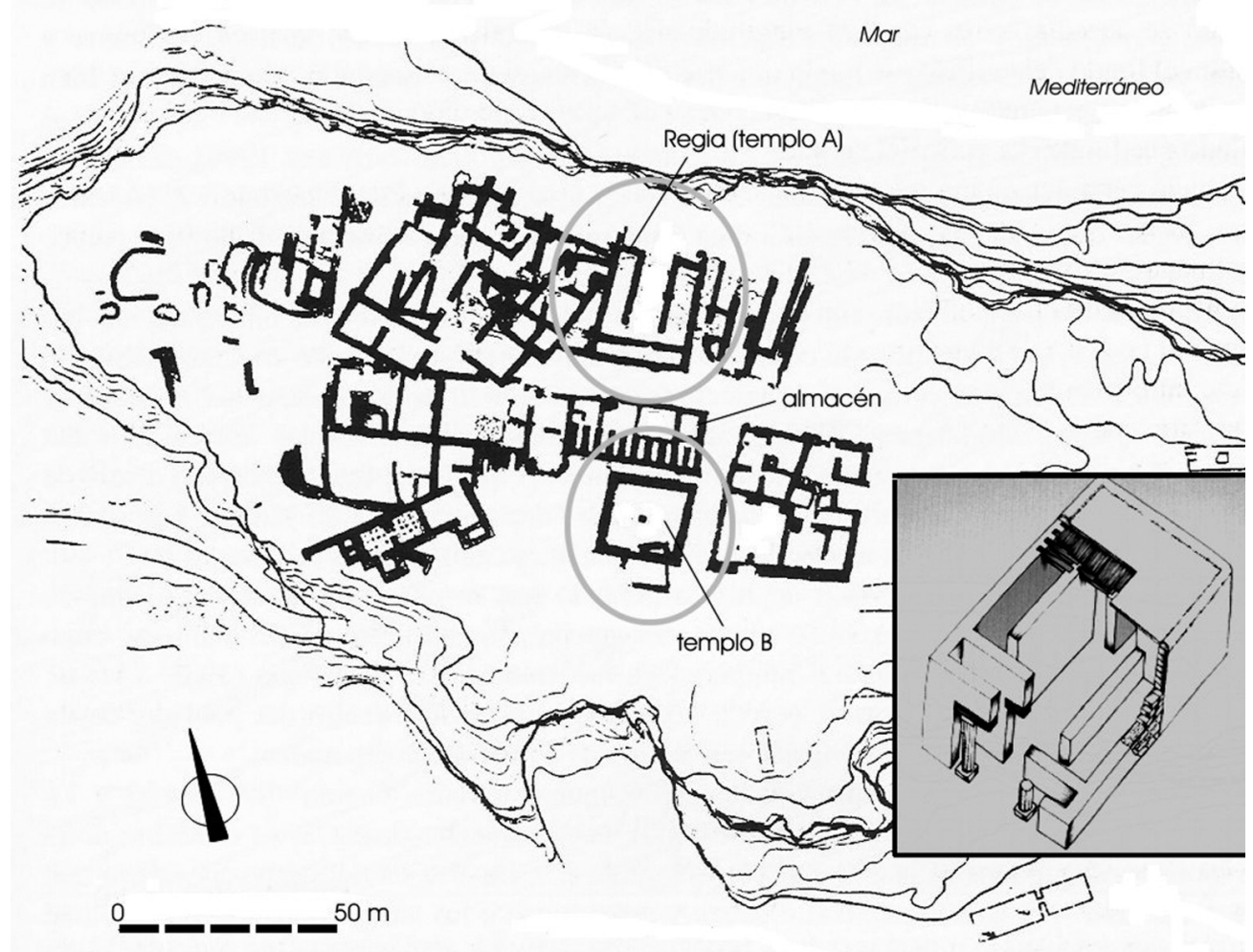

Figura 2: Plano de la Illeta dels Banyets (El Campello, Alicante) modificado a partir de Llobregat, 1985, y propuesta de reconstrucción axonométrica (Olcina, 2005).

Baelo Claudia (Tarifa, Cádiz), dada su planta alargada junto con otras cuestiones arquitectónicas o materiales (Bendala, 2006, 378; 2010, 473).

La planta del templo A de El Campello responde a influjos púnicos, y así fue visto desde un principio. Se trata de una estructura que se repite con cierta profusión en los ambientes fenicios y con frecuencia en diversos núcleos urbanos centro-mediterráneos, como la propia Cartago, Kerkouane o Mozia. Aunque E. Llobregat identificó, pensamos que con acierto, el espacio como de influencia púnica, los más recientes estudios por él publicados demuestran que terminó adscribiéndolo finalmente a modelos etruscos por sus paralelos estilísticos y culturales (Llobregat, 1985, 104; 1991, 326 y ss.). También las reconstrucciones gráficas que realizó del templo A apuntan en esta dirección, puesto que siempre lo remató con una cubierta a doble vertiente muy del gusto etrusco-itálico, a excepción de algún boceto inicial en el que lo remató con una techumbre plana más próxima a los modelos semitas con las dos columnas que enmarcaron el acceso (Olcina, Martínez y Sala, 2009, fig. 183, 163). El detallado estudio de sus diarios e informes destaca su cuidado método de intervención arqueológica y registro y ofrece un amplio volumen de información de gran valor para la interpretación de su funcionalidad y de su adscripción cultural, así como también para la actual puesta en valor y musealización llevada a cabo por los técnicos del Museo Arqueológico Provincial de Alicante-MARQ.
Destacamos lo detallado de las descripciones realizadas durante el proceso de excavación del templo A con alusión tanto a los materiales contenidos en cada uno de los estratos y de las estancias, como a la composición de los muros, incluyendo la pigmentación rojiza de los revestimientos y el amarillo de las dos columnas ochavadas del acceso (Olcina, Martínez y Sala, 2009, 113) que lo harían destacar, por su colorido, por encima del resto de las estructuras de la Illeta dels Banyets.

\section{LOS CENTROS DE MERCADO FENICIOS Y PÚNICOS ¿UN PRECEDENTE?}

Como ya hemos tenido ocasión de referir, el modelo arquitectónico caracterizado por una estructura rectangular en planta, dividida en tres naves con la central generalmente de mayor anchura y sin podio, responde a un prototipo oriental cuya incidencia en las arquitecturas mediterráneas occidentales durante la Protohistoria se puede explicar a partir de un modelo teórico de corte difusionista que ya hemos tenido ocasión de exponer en otros trabajos (Prados Martínez, 2004; 2007). Esta estructura arquitectónica tripartita que ha sido interpretada frecuentemente como «almacén» penetró, de forma paulatina, en las culturas arquitectónicas occidentales dentro de lo que se ha venido llamando fenómeno orientalizante, que se inició a partir de la presencia comercial semita -fenicia- hacia el siglo 


\section{田囯四監}

Figura 3: Plantas de viviendas sirio-palestinas (según Braemer, 1982).

IX a.C. en determinados puntos del Mediterráneo central y occidental y en la costa atlántica del norte de África. La razón de la generalización de estos modelos hemos de buscarla en su funcionalidad manifiesta y en su explícita tipificación arquitectónica, que unía, a su estructura fácilmente reconocible e identificable en el marco urbano o rural en la que se alzaba, un uso muy bien definido que respondía perfectamente a las necesidades de la comunidad.

Este proceso de identificación de los espacios arquitectónicos en razón de su tipificación determina, pues, que debieron tener, igualmente, una similar funcionalidad. La concatenación de los distintos elementos arquitectónicos debió dotar a los edificios de estructuras similares a las que ofrecen las lenguas, es decir, los elementos se pondrán como signos arquitectónicos que, paralelamente a los signos lingüísticos, parecerían constar de un significante y un significado y así podrían ser leídos de forma unitaria. Aplicando un análisis semiológico a la arquitectura, de gran utilidad para defender los planteamientos que aquí traemos, la pluralidad de la fenomenología arquitectónica tiene su paralelismo en la pluralidad de las lenguas (Brandi, 1967, 35), y muchos de los espacios que presentan aspectos similares, debieron tener usos parecidos, a pesar de los saltos espacio-temporales que bien podrían suponer el principal apoyo de los argumentos contrarios.

Por estas razones, si analizamos con detenimiento estos modelos arquitectónicos, recorriendo las prolíficas vías de la semiótica, es fácil detectar la influencia remota, aunque directa, de los palacios orientales, en concreto de aquellos que fueron edificados en las fértiles tierras mesopotámicas. Al frente de dichos palacios sabemos que se encontraba un rey-sacerdote ${ }^{3}$, que, además de las funciones políticas y religiosas, mantenía el control sobre los excedentes de la producción y su redistribución. Esa es la clave para tratar de entender la repetición o imitación de este modelo tan funcional. Esa estructura palacial, que hacía las veces de almacén y de lo que hemos denominado «centro de mercado», siguiendo a $\mathrm{M}^{\mathrm{a}}$. E. Aubet, marcó las pautas de lo que serían después las estructuras que nos

3. Como el lawarna de los textos hititas, que aglutina en su figura el papel de rey, juez supremo, sumo sacerdote y jefe del ejército. ocupan, tanto por el tipo de arquitectura, como por su situación y sus funciones (Aubet, 2000).

Esta tipificación de la que venimos hablando provocará la construcción de estos modelos arquitectónicos en diferentes lugares, imbuidos siempre en la oleada cultural orientalizante, siguiendo la misma estructuración de la planta, es decir, aquella que se manifiesta en tres espacios, con el central más ancho, y que refleja reminiscencias de las clásicas viviendas domésticas de Siria (Fig. 3) de los tipos II.A.3 y III.4 de F. Braemer (Braemer, 1982), señaladas comúnmente como precedente (Almagro y Domínguez, 1988-1989; AlmagroGorbea, 1990; Aubet, 2000, entre otros). También hay que valorar el reflejo directo de estas estructuras siríacas en construcciones fenicias occidentales, como las casas de Sa Caleta (Ibiza), y en otras estructuras de génesis fenicia de la costa malagueña, donde de nuevo nos encontramos ante el uso de módulos habitacionales en tridente 4 que, además, presentan el uso de una modulación canónica mediante codos fenicios de entre 52-55 cm (Ramón, 2007; Gailledrat, 2007, 114 ss.; Jiménez Ávila, 2009; Arnold y Marzoli, 2009).

Debieron ser las elites urbanas enriquecidas por el comercio las que controlaron estos centros de mercado fenicios y púnicos, derivados, como hemos visto, de los prototipos orientales regidos por autoridades monárquicas sacralizadas. Aunque los datos a este respecto son exiguos, probablemente algunos de estos centros fueron controlados por personajes vinculados a las dinastías reales (algo más probable en los casos orientales -como en los centros de Hazor o Al Mina [Wooley, 1938], por ejemplo-), mientras que los occidentales debieron estar gestionados por miembros de las familias (o de las agrupaciones o compañías privadas) que dirigieron las empresas comerciales a gran escala y que promovieron desde las metrópolis orientales la fundación de los asentamientos «empóricos» o las factorías en el Mediterráneo central y occidental.

En los centros de mercado fenicios y púnicos, auténticos precedentes de las llamadas regiae ibéricas que estudiamos aquí, se dan una serie de constantes: por lo general, se ubicaron cerca de las murallas o de las puertas de acceso a las ciudades y se convirtieron rápidamente en centros principales de transacción, ocupando lugares que eran confluencia de vías de comunicación y dominando rutas de comercio, tanto terrestre como marítimo, además de regiones de producción agrícola o ganadera. Uno de los ejemplos más característicos es el edificio «C» de Toscanos (Schubart y Maas, 1984), construido a principios del siglo VII a.C. (Schubart, 2002, 79), que es más un

4. Caracterizado por una estructura de planta rectangular compleja, con un acceso ocupando el eje axial del edificio que da a un distribuidor de planta rectangular sobre el que se abren los tres vanos de acceso a las tres estancias principales, con la central, por lo general, de mayor anchura (Jiménez Ávila, 2008, fig. 11, 119). 


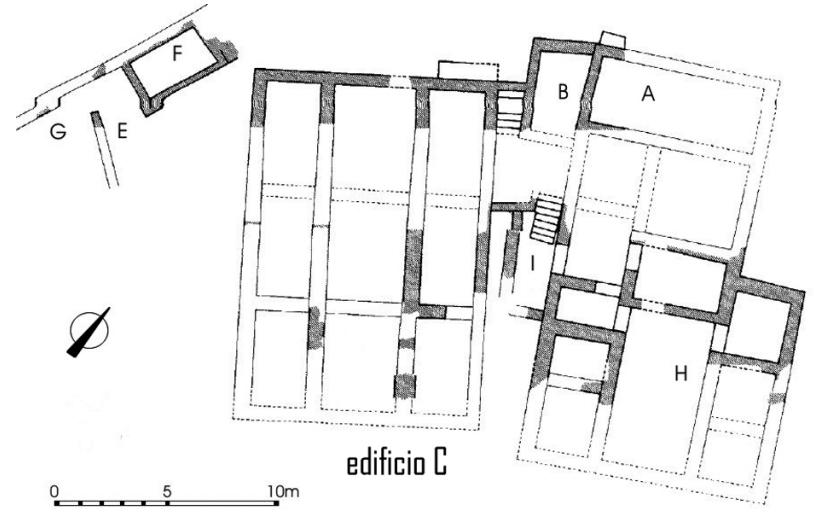

Figura 4: El edificio "C" de Toscanos, en su contexto urbano (según Schubart, 2002).

centro de mercado, regido por la autoridad urbana (esa misma que se entierra en los ricos hipogeos del entorno como los de Trayamar), que un simple almacén (Fig. 4). Parece, además, que en él no aparecieron ánforas (Docter, 1997). Según Aubet (Aubet, 2000), el conocido edificio $\mathrm{C}$ de Toscanos sería un buen ejemplo de esos centros de mercado señalados. El edificio malagueño, orientado SE-NO, responde a un módulo canónico que empleó un codo de 50-55 cm y presenta de nuevo la nave central de una anchura mayor que las dos laterales (la nave central mide 3,60 m de ancho y las laterales 2,40 m). Además, ésta se encuentra empedrada y, muy posiblemente, conformaba un espacio de más altura que las laterales, posiblemente con un segundo piso (Arnold y Marzoli, 2009, 443 ss.). Cabe la posibilidad de que la planta inferior estuviese ocupada por el almacén, mientras que el segundo cuerpo se emplease como vivienda.

La complejidad arquitectónica de este espacio provoca que hoy sea interpretado por sus excavadores como una gran casa o un edificio de carácter público más que como una estructura simple de almacenaje o un templo. Se distingue del resto de construcciones tanto por su tamaño como por su planta, su estructura y su calidad constructiva (Schubart, 2002, 82; Arnold y Marzoli, 2009, 450). Esta nueva identificación del edificio de Toscanos con una construcción de carácter público redunda en la cuestión aquí presentada y supone todo un procedente directo de las regiae objeto de análisis, tanto por su estructura -lo que ya había sido señalado- como, sobre todo, por su funcionalidad (Fig. 5).

El caso de Toscanos, con unas dimensiones de 10 x $5 \operatorname{codos}(1$ codo $=50 / 55 \mathrm{~cm}$ aprox. $)$, se repite en el cercano asentamiento fenicio del Morro de Mezquitilla, con la planta central más ancha y alta (Schubart, 1997, 21 ss.). Existen variaciones en la tipología de las viviendas de Morro de Mezquitilla, aunque las más cuidadas presentan una similar estructuración tripartita. En cualquier caso, estas edificaciones, de carácter urbano, se adaptaron al trazado de los ejes viarios.

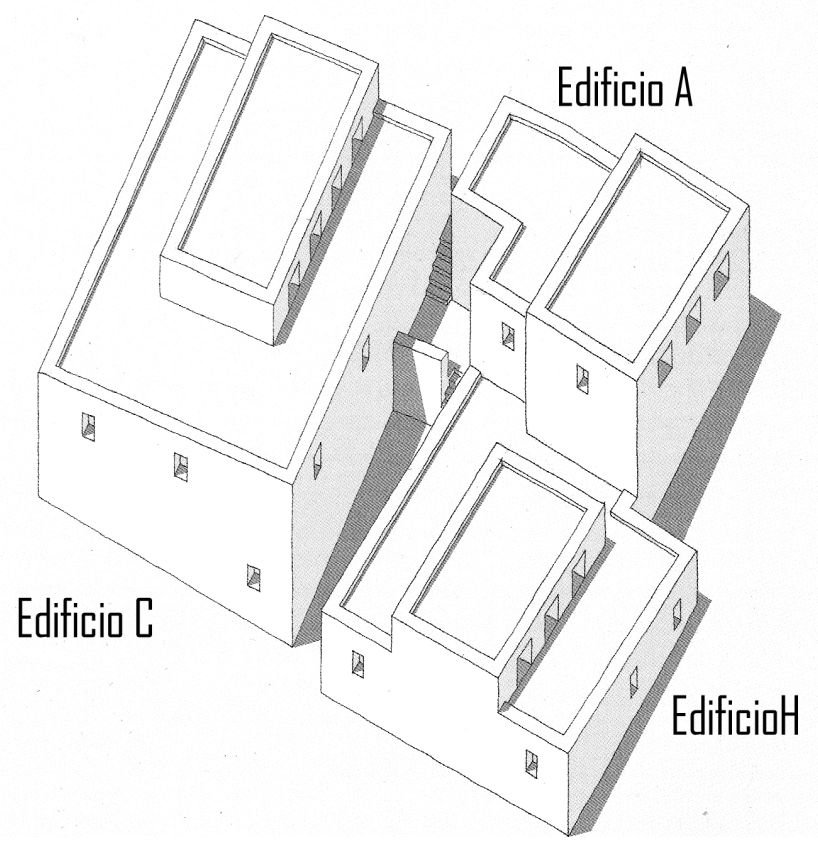

Figura 5: Propuesta de reconstrucción del edificio «C» de Toscanos (según Arnold y Marzoli, 2009).

Lo mismo sucede en el caso del almacén de la puerta sur de Mozia, en el stagnone di Marsala (Sicilia), en el que aparecen vestigios relacionados con almacenaje (ánforas), con comercio al por menor (pesos de plomo), así como también con talleres de manufactura metálica, todo ello en un mismo edificio, con un esquema común en otros lugares, y en una posición central y destacada dentro de la estructura del asentamiento (Tusa, 2000).

La tipificación arquitectónica de todos estos edificios se hace patente al analizar sus plantas desde el punto de vista tipológico y sus similares técnicas constructivas. Dicha tipificación supondría el reconocimiento del edificio por cualquier persona, no sólo por aquellas que habitasen en el mismo espacio urbano, sino por cualquiera venida desde cualquier otro punto cercano o alejado dentro del ámbito mediterráneo, que sabría rápidamente dónde dirigirse si en su voluntad estaba el entablar cualquier tipo de relación comercial o económica, o encontrar quien sancionase y certificase los pesos y medidas de los productos adquiridos o intercambiados. A este respecto cabe añadir también el papel que debieron jugar los revestimientos y las tonalidades llamativas con las que fueron decorados en el exterior los edificios, a menudo con un carácter sagrado o ritual -como el uso del color rojo-. Contamos con el referido caso del templo A de la Illeta de El Campello y hemos de hacer extensible esta misma cuestión, con mucha probabilidad, al resto de edificios de estas características.

Junto con el centro de mercado tripartito ubicado en la puerta sur de Mozia, cabe destacar otros espacios singulares en este mismo yacimiento que se 


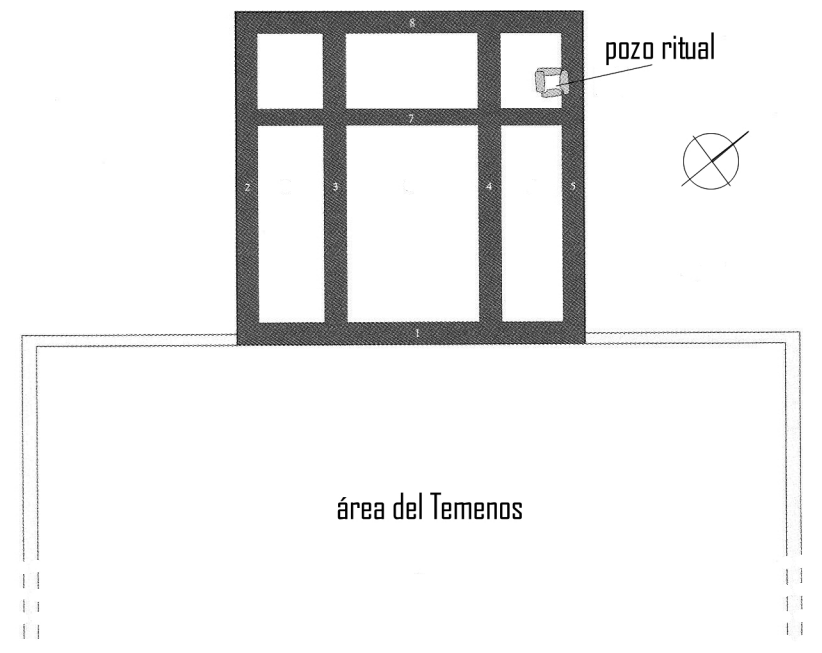

Figura 6: Planta del Cappidazzu de Mozia (Sicilia) y su área sacra (a partir de Nigro, 2009).

deben tomar en consideración, al repetir un idéntico modelo de planta. El llamado Capidazzu de Mozia es una de las tres áreas sacras de la ciudad (junto con el templo del Kothon y el santuario del tofet). Se ubica en una zona de puerta y presenta una cronología bastante amplia, que ha sido dividida en diferentes fases. Una primera fase, entre los siglos VIII y VI a.C., caracterizada por un zócalo de mampostería cuidada con un alzado en adobes, y una segunda fase que supone la construcción de un nuevo edificio en el mismo lugar, aunque con una orientación acorde con el trazado urbano. Este nuevo edificio de la segunda fase presenta un modelo tripartito de gran interés para el tema que aquí nos ocupa, pues se observan en él las dos cámaras laterales más estrechas y la central más ancha, un esquema bastante habitual en la edilicia de origen fenicio-púnico, como se ha visto en el caso del edificio $\mathrm{C}$ de Toscanos. Las fases 3 y 4 del Capidazzu, fechadas a partir del siglo V-IV a.C., mantienen la misma disposición (Fig. 6) y son las que presentan más concomitancias con los modelos del área ibérica que analizamos, tanto desde el punto de vista arquitectónico, como desde el cronológico. Su construcción, como hemos mencionado, ya arrancaba en el siglo VIII a.C. y presentaba una modulación fenicia canónica realizada a partir de la colocación de bloques de calcarenita de $2 \times 1$ codos de $0,525 \mathrm{~m}$ en una estructura cuasi cuadrada de $15,11 \times 15,80 \mathrm{~m}$ con tres naves, la central de 12 codos de anchura $(6,30$ m) y dos laterales de 6 codos, es decir, de 3,15 m de ancho (Nigro, 2009, 247). La repetición del modelo de planta, de las dimensiones en ambas estructuras e, incluso, de la orientación a lo largo de los siglos denota la importancia de un modelo arquitectónico claramente ritualizado y tipificado, y que fue proyectado por los fenicios en otros centros, como en el caso de Toscanos, y que pudo suponer la génesis de los posteriores desarrollos urbanos en sus proximidades, como se señala en el caso de Mozia (Nigro, 2009, 266).

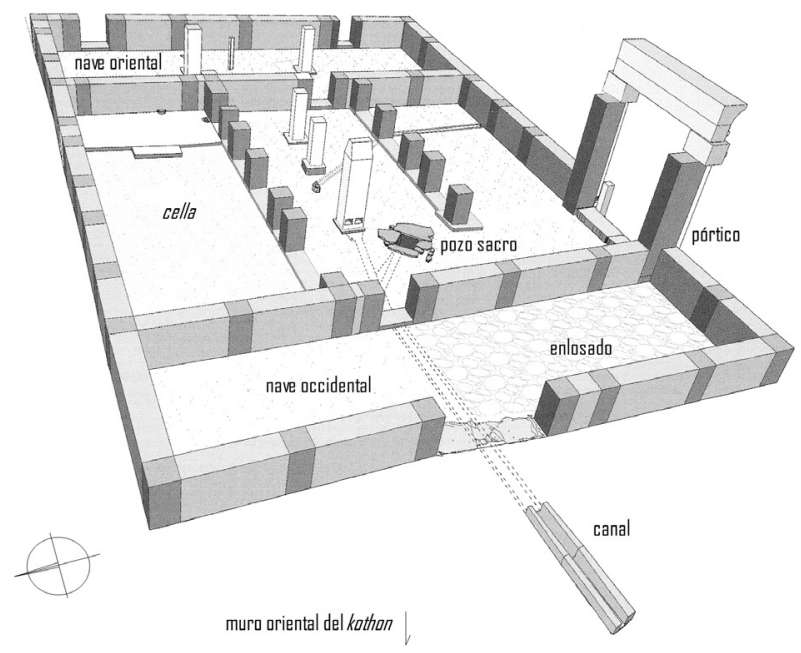

Figura 7: Axonometría del templo del Kothon de Mozia (según Nigro, 2009).

Otro de los edificios de carácter sacro de Mozia es el templo ubicado junto al Kothon o puerto artificial. De nuevo nos encontramos ante un modelo templario tripartito orientado este-oeste, como el Capidazzu, y ubicado también junto a una zona de acceso a la ciudad, en este caso la meridional. Este edificio, que presenta también una amplia cronología, (siglos VIIIIV a.C.), ha sido excavado en los últimos años ${ }^{5}$ y ha aportado numerosas novedades. A la planta tripartita con la nave central más ancha cabe añadir que presenta un acceso lateral con la puerta enmarcada por dos columnas (a las que se adscribe el capitel protoeólico encontrado en la zona). Asimismo, han aparecido en la excavación fragmentos de la cornisa de gola egipcia que subrayan la monumentalidad del edificio. En el centro del espacio sacro fue hallado un obelisco y otros elementos de índole religiosa.

Este recientemente publicado templo del Kothon de Mozia (Sicilia), fechado en su fase más antigua en el siglo VI a.C., representa otro modelo más que comparte una misma estructura en lo que concierne a la planta, modulación (en codos de 0,525 m), y en el que no se duda de su adscripción religiosa (Fig. 7), presidiendo el estanque con la fuente ritual -anteriormente interpretada como puerto artificial y hoy desestimada esta funcionalidad tras su limpieza y excavación- (Nigro, 2009, 259). Este templo se desarrolla orientado este-oeste y en la cabecera de un espacio abierto, interpretado como temenos sagrado (Nigro, 2009, 246), con paralelos en el Ma'bed fenicio de Amrit (Siria). El esquema constructivo del templo del Kothon repite un modelo tripartito caracterizado

5. Cuyos resultados científicos fueron presentados por el profesor L. Nigro (Università de La Sapienza) en el Congreso sobre urbanística fenicia organizado en Roma (febrero de 2007) por el Instituto Arqueológico Alemán y recientemente publicado en Helas y Marzoli (eds.), 2009. 


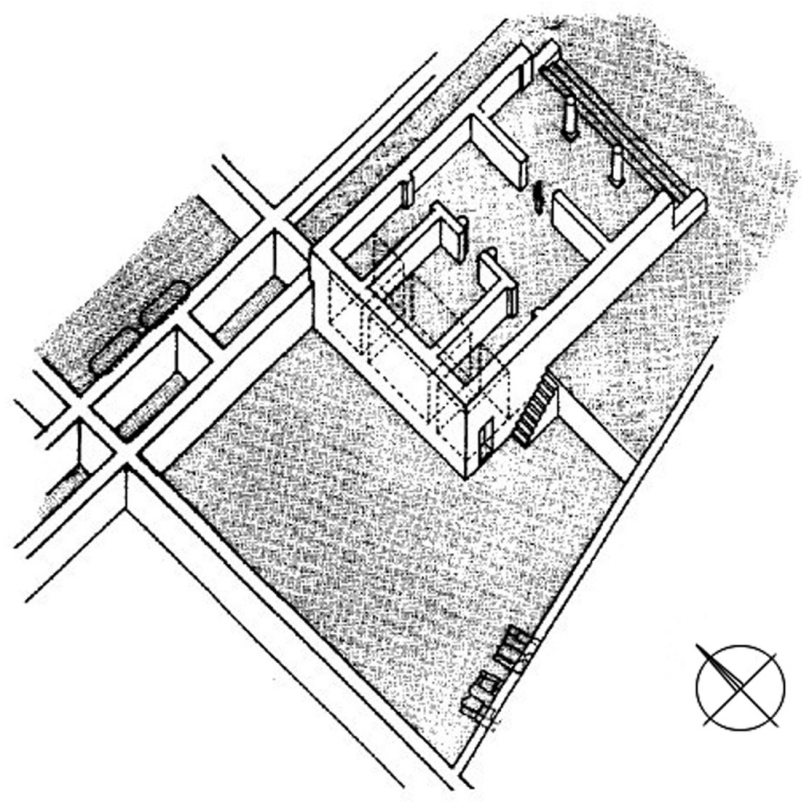

Figura 8: El santuario ubano de la Rue Ibn Chabaât (Cartago), según la propuesta de Rakob, 1998.

indudablemente como sagrado, y que tenía su precedente directo en el mismo entramado urbano de la ciudad de Mozia en el anteriormente citado santuario del «Cappidazzu», ubicado al norte del islote (Tusa, 2000, 1401). La metrología empleada en esta construcción es de nuevo canónica e idéntica a la que se empleó en el área sacra de la ciudad que acaba de ser referida anteriormente.

Otro edificio que podemos incluir es el templo excavado en la calle Ibn Chabâat de Cartago (Fig. 8), si bien este último con una cronología algo más reciente (Rakob, 1998, 29-32). Este investigador busca paralelos en templos de tradición púnica estructurados en tres naves, como los que señala $P$. Pensabene en el entorno de Cartago (Pensabene, 1989, 252), que tienen su origen en Próximo Oriente y que presentan una misma modulación y orientación que los que estamos señalando. Plantas similares se pueden observar en otros centros urbanos púnicos centromediterráneos como Kerkouane (Túnez), donde, fuera del entramado urbano ortogonal de la ciudad, se dibujan en planta otras construcciones tripartitas aisladas y que presen$\tan$ una estructura especial que las hace distintas al resto de las viviendas, caracterizadas por disponerse en enfilada (Fantar, 1984). En la zona sureste de la ciudad, junto a la línea de costa, aparecen unas casas de planta compleja entre las que destaca una claramente residencial con un peristilo columnado y otra de carácter tripartito con una funcionalidad no tan clara, y que presenta un acceso entre columnas que remarca su carácter «especial», quizás templario (véase la planta en Fantar, 1998, 114), y que ya habíamos relacionado con las aquí estudiadas (Prados Martínez, 2004, Fig. 3B, pág. 175).

\section{EL PAPEL DE LA REGIA EN EL CONTEXTO COMERCIAL Y RELIGIOSO IBÉRICO (SIGLOS V-IV A.C.)}

Como hemos ido adelantando, las estructuras que abordamos en estas páginas han sido definidas como regiae al haberse identificado como complejos de carácter palacial (Almagro y Domínguez, 1988-1989). La cuestión es que quizás esta interpretación encaja con un momento cronológicamente más antiguo, en el que triunfó un modelo social de jefaturas personales o aristocracias formadas por héroes y dinastas de corte oriental, que fueron los que necesitaron de esos palacios o palacios-santuario como Cancho Roano (Gusi, 1997, 174; Almagro-Gorbea, 1990). La cuestión es que los palacios tenían un tamaño mucho mayor que los que aquí estudiamos, más modestos en dimensión. Los edificios que analizamos aquí encajan más en un modelo de sociedad abierta al exterior, inscrita en el marco de las relaciones comerciales mediterráneas y liderada por régulos locales o dinastas interrelacionados y condicionados, en muchas ocasiones, por la presencia de extranjeros viviendo en sus mismos poblados o habitando otros ubicados en el entorno próximo.

Los edificios B y C de Cancho Roano (Fig. 9) han sido relacionados con la existencia de una figura notable, en concreto un rey-sacerdote, aunque no se ha entendido el complejo como la residencia permanente del monarca (Celestino, 1997, 379), una afirmación que nos parece clave para tratar de reconstruir la funcionalidad de este tipo de espacios. Así pues, tanto en el caso de las fases más antiguas de Cancho Roano como en el de las supuestas regiae ibéricas, no observamos que se trate de residencias y sí de otras estructuras con vinculación sagrada, relacionadas con el comercio y con el reparto de mercancías o excedentes. En Cancho Roano B y C se argumenta que el aislamiento del complejo impediría que se tratase de la residencia de uno de estos reyes-sacerdotes, aunque no se descarta la posible existencia de un pequeño grupo de sacerdotes $\mathrm{u}$ otras autoridades religiosas menores (clero o civiles que asumieron funciones de tipo cultual) que se ocupasen de la gestión del edificio, aunque el poder estuviese bajo una autoridad que habitase en un centro urbano del entorno.

Para otros autores, como hemos visto, Cancho Roano reúne los requisitos teóricos de un palacio de tipo sacro, perteneciente a un personaje de los que presidieron la cúspide de la pirámide social, y que ostentaba un poder sacro (Almagro y Domínguez, 19881989, 345). Según esta lectura, este palacio fue una construcción monumental destinada a albergar al rey y a su corte. Evidentemente, el caso de Cancho Roano -sobre todo en sus primeras fases- no reúne las condiciones propicias, dado su escaso tamaño. De todas formas, parece que la lectura social ofrece referencias suficientes como para comprobar que el modelo organizativo de la sociedad orientalizante peninsular y de la sociedad oriental era bastante semejante, lo que 

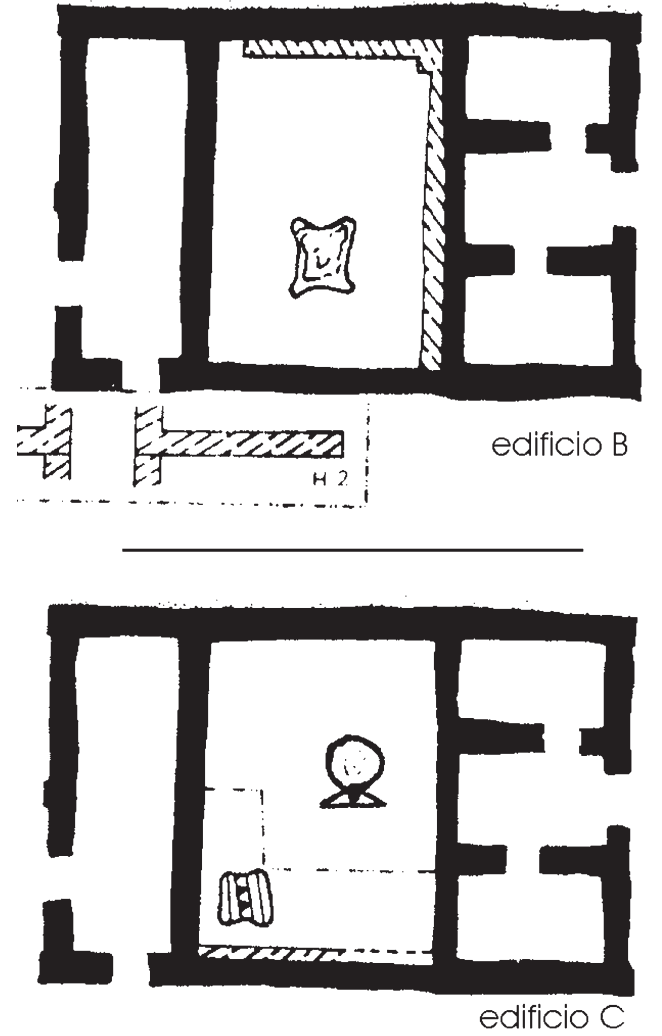

Figura 9: Los edificios $\mathrm{B}$ y $\mathrm{C}$ de Cancho Roano, precedentes del posterior palacio (según Celestino, 2001).

desembocó en la repetición de un modelo constructivo y funcional similar. En la misma línea, Almagro y Domínguez inscriben también el templo A de El Campello dentro de su catálogo de palacios o residencias regias (Almagro y Domínguez, 1988-1989, 366), aunque su pequeño tamaño y sus características arquitectónicas y funcionales lo alejan de esa adscripción, como veremos con más detalle a continuación.

El problema del uso del término «palacio» es que implica un determinado sistema social, muy concreto. El palacio debe reunir las condiciones necesarias para poder desempeñar las diversas funciones que entraña, tales como las de vivienda, sede administrativa, ideológica y social. El caso de los edificios $\mathrm{B}$ y $\mathrm{C}$ de Cancho Roano no encaja, aunque sí estamos de acuerdo en que se trató de un edificio de poder y de prestigio. Puede que la definición que realizó Maluquer de «centro comercial de trueque» (Maluquer, 1981, 274) sea la mejor a nuestro parecer, auténtico referente -y modelo- para los edificios que estamos estudiando en este trabajo, a los que definimos prácticamente de la misma manera. En Cancho Roano se recuperaron numerosos elementos vinculados con el intercambio y con el control económico (platos de balanza, ponderales e incluso sellos de propiedad), y en cambio pocos objetos que se puedan relacionar con la función religiosa del espacio. Además, este modelo tripartito bien representado en el Mediterráneo oriental y central, desde el hallazgo de Cancho Roano (VI a.C.), empieza a observarse con frecuencia en la Península Ibérica, en yacimientos como La Mata (VI a.C.) o Fernão Vaz de Ourique en Portugal (V a.C.) (Rodríguez Díaz, 2007). Además, al igual que en Cancho Roano, hay que tener en cuenta los ponderales y platillos de balanza que aparecen en algunos de estos contextos, caso de El Palomar o Herdade da Sapatoa (Jiménez Ávila, 2008; Mataloto, 2008), y que podemos vincular también con el control de los pesos y las medidas en las transacciones comerciales que allí se llevaban a cabo. Cabe señalar que en ninguna de las estructuras mencionadas existe un podio, elemento que dificultaría un uso cotidiano y funcional al obligar la construcción de una escalera de acceso.

Para explicar el papel de las regiae es importante replantear la incidencia del comercio colonial sobre la cultura ibérica, así como entrar a valorar el papel de los templos y las estructuras religiosas en el marco de las transacciones comerciales. Aparte de los testimonios materiales directos e indirectos con los que se cuenta para defender el papel de los santuarios y templos como lugares hábiles para la realización de pactos y transacciones comerciales ${ }^{6}$, contamos con alguna referencia textual muy llamativa, como la de Arriano, en la que se relaciona la construcción de un templo por Alejandro Magno con las transacciones comerciales:

Alejandro encargó construir un templo en la ciudad de Alejandría [...] encargó también que el templo se denominase Hefesteión, nombre que debía inscribirse en los contratos que los comerciantes conviniesen allí entre sí.

(Anábasis, VII, 23, 7)

Existen problemas en la investigación sobre el comercio en época ibérica, derivados de la propia metodología empleada y de la naturaleza de la documentación, dada la falta de la aplicación de nuevos modelos antropológicos (Santacana y Belarte, 2003, 127). Se trata de un proceso de transformación centrado en una serie de modelos que comportan cambios que tienen reflejos en la cultura material. Esto se observa en una complejidad creciente del sistema social, con una mayor complejidad también en los mecanismos económicos, que trajeron consigo un desarrollo de núcleos especializados (por ejemplo, los poblados vinateros como el Alt de Benimaquía o La Quéjola) y la diferenciación en los núcleos habitados entre las zonas de ocupación y las áreas industriales, así como una jerarquización de esos mismos núcleos. Esta mayor complejidad provocó la fortificación de algunos centros, que aumentaron

6. Recordemos al respecto el episodio de la expulsión de los mercaderes del templo recogida en el Nuevo Testamento (Mateo 21, 12-17; Lucas 19, 45-46 y Juan 2, 14-16) «Llegaron a Jerusalén y, entrando en el templo, se puso a expulsar a los que allí compraban y vendían...» «...y no permitía que transportaran objetos por el templo» (Marcos 11, 15-17). 
los recursos estratégicos para defender las salinas o minas, o las áreas de producción agrícola. En el mundo ibérico, desde finales del siglo $\mathrm{V}$ hasta la disolución de la cultura ibérica en el II a.C., se observa la paulatina jerarquización de algunos núcleos organizados en oppida con espacios de producción restringida y zonas de captación de recursos exclusivos de cada unidad de asentamiento, ubicados junto a las principales vías de comunicación, que funcionaron, además, como focos de atracción del poblamiento (Grau Mira, 2002, 253). En muchas ocasiones, en los espacios liminales de cada uno de los territorios controlados por estos $o p$ pida, aparecieron santuarios o estructuras aisladas de carácter religioso, y entre éstas podemos entender la función que pudieron desempeñar algunos de los que traemos aquí, caso de El Chorrillo de Petrer o las Tres Hermanas de Aspe, ambos ubicados en la cabecera de sus respectivos territorios lo que los pudo «interconectar» comercialmente (y también «espiritual» y puede que «jurídicamente»).

Al respecto, es importante destacar que muchos de estos espacios se ubicaron en zonas llanas, no siempre bien defendidas, como se aprecia en Cancho Roano o en los ejemplos de Tallada IV de Caspe, en la provincia de Zaragoza (Melguizo, 2005). Tallada IV se ubica en una zona baja, plana y rodeada de diversos oppida fortificados que son realmente los que protegen el edificio, que preside una planicie óptima para la realización de intercambios comerciales, compras y ventas de ganado y animales domésticos, etc. Parece una constante la ubicación de estos espacios tripartitos en zonas accesibles y poco o nada defendidas desde el punto de vista artificial, aunque, como en el caso de las Tres Hermanas de Aspe o en el Chorrillo de Petrer, se ubiquen en altura. En ninguno de estos ejemplos encontramos murallas o fosos que enmarquen el espacio en el que se sitúan. Parece que el propio carácter «especial» de estas construcciones, y su posición entre territorios, las dota de cierta «inviolabilidad», que debió ser respetada por los habitantes de las comunidades vecinas, que fueron los que hicieron uso (ritual y económico/comercial) de ellas.

El modelo clásico de las viviendas ibéricas fue adquiriendo una mayor complejidad y un mayor tamaño, según parece, como reflejo del impacto que tuvo la arquitectura fenicia en el Levante hispano. Así se fueron duplicando el número de estancias y ampliando el tamaño de las mismas. Este hecho tiene relación con la fundación de diversos establecimientos coloniales en la zona valenciana, que transmitieron un conjunto de novedades tecnológicas y tipológicas (Abad y Sala, 1993; 2001; Moret, 2001-2002; 2002). Quizás podamos explicar la evolución del modelo definido como regia por esta misma razón, ya que se trató originalmente de una arquitectura compleja de origen oriental, solo que, en este caso, derivada hacia otro tipo de estructura arquitectónica con una funcionalidad diferente a la estrictamente doméstica. Existen otros indicadores para rastrear la transmisión de este modelo constructivo, como los de tipo económico. Éstos muestran la reserva de productos en grandes proporciones, que se plasmó en la construcción de silos de almacenaje en la zona ibérica catalana, o en la de almacenes en otras zonas levantinas meridionales.

El desarrollo comercial y económico coetáneo a la aparición de las llamadas regiae encaja con el momento de la eclosión de la figura de los big man, es decir, nuevos líderes sociales que acumularon elementos de prestigio con una función niveladora y redistribuidora (Santacana y Belarte, 2003, 139). En algún caso, estas figuras tuvieron evidentes connotaciones de tipo religioso, siendo, pues, quienes pudieron habitar directamente o dirigir, desde la distancia, las actividades que se desarrollaron en el marco de las regiae. Entre los objetos del comercio vinculados con estos líderes sociales destaca el vino como elemento de prestigio, al ser un producto exótico y estimulante. El vino, que tuvo una clara función social, sería un instrumento empleado en estos ambientes para delimitar los rangos sociales, poniéndose, por ello, al servicio de aquellos que controlaron las redes de distribución. Esa es la razón, muy posiblemente, de la aparición de vasos y otros elementos de la vajilla cerámica de lujo en el interior de las regiae relacionados con el consumo del vino (esto se observa, por ejemplo, en Aspe, en el templo A de la Illeta de El Campello ${ }^{7}$, en Alarcos y en los complejos palaciales del suroeste, en los que el vino y su vajilla asociada tuvieron un papel preeminente). En todos estos casos la vajilla sería en sí misma un indicador de prestigio que se asoció al poder y al rango social. Cabe reseñar además, y en este sentido, la aparición de un pequeño lagar junto a los templos de El Campello, con unas características técnicas muy particulares, que lo acercan a los de tipo púnico, dados los revestimientos de las piletas con morteros de cal próximos al opus signinum u hormigón hidráulico (Olcina, Martínez y Sala, 2009, 182 y Fig. 300).

En otros trabajos se han tratado de aplicar análisis microespaciales centrados en el ámbito de los yacimientos ibéricos, así como estudios para determinar la jerarquización de los distintos espacios arquitectónicos en el marco del poblado ibérico (Gracia, Munilla y García, 1997, 445 y ss.). Dentro de estos estudios se han observado los centros redistribuidores objeto de estudio dentro de un tercer nivel ${ }^{8}$, es decir, los espacios arquitectónicos representativos del poder político/comunal, siendo templos como expresión de la estructura ideológica de una comunidad o como plasmación del poder de un grupo social determinado, donde la acumulación de bienes de prestigio

\footnotetext{
7. En una de las naves laterales aparecieron páteras áticas de barniz negro y cerámica ibérica pintada con decoración a bandas (Olcina, Martínez y Sala, 2009, 112).

8. Siendo los dos primeros niveles el de las viviendas y el de los edificios con funciones de almacén, residencia o culto (Gracia, Munilla y García, 1997, 446).
} 


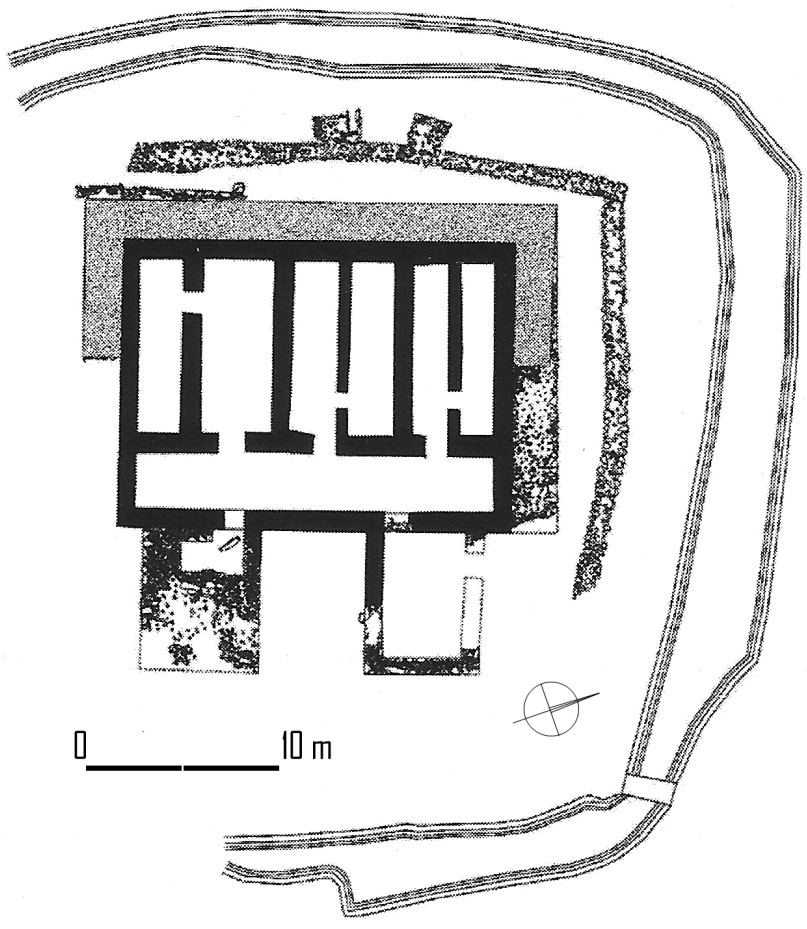

Figura 10: El complejo palacial de La Mata (Campanario, Badajoz), según Rodríguez, 2004.

provocaría la construcción de estos modelos tipificados siguiendo los esquemas constructivos edilicios de tipo mediterráneo.

Los productos importados desde estos centros tuvieron que ser, en su mayoría, alimentarios, por encima de los bienes de prestigio, dado el tipo de estructuras de almacenaje de excedentes que se emplearon, y que podemos rastrear también en los vasos contenedores que se documentan en su interior. Los edificios contestanos se encuentran en la zona de influencia de Ibiza, hecho este bien comprobado a través del estudio de los materiales (sobre todo los contenedores anfóricos) y a través del análisis de las corrientes y los regímenes de vientos, muy favorables para el trasiego constante por la zona denominada «canal de Ibiza» o «canal de Jávea», que discurre frente a la costa del norte de la actual provincia de Alicante. No olvidemos, asimismo, que la isla balear y el litoral contestano mantienen una relación de visibilidad en los días propicios. La presencia en esta zona de envases procedentes del área gaditana es también destacable, aunque los porcentajes no son, ni mucho menos, tan significativos (Sanmartí, 2000, 315). Como ya indicó Morel, la región costera contestana «se ubicó en el meollo comercial cartaginés», sobre todo a partir del siglo IV a.C. La presencia de vajilla griega en esta zona habría que entenderla dentro de un panorama económico-comercial púnico (Morel, 1994, 337; Sala, 2001, 297). Incluso lugares apartados como Ampurias u otros centros del área catalana, tradicionalmente inscritos en los circuitos comerciales griegos, pudieron tener una importante imbricación con la estructura comercial cartaginesa, pudiendo funcionar como puntos destacados en la redistribución de productos de origen púnico (Sanmartí, 2000, 315), papel este que bien podríamos atribuir también al complejo singular de la Illeta de El Campello.

\section{ANÁLISIS ARQUEOARQUITECTÓNICO DE LA LLAMADA REGIA IBÉRICA. ORIGEN, PARALELOS Y PAUTAS CONSTRUCTIVAS}

Uno de los campos más atractivos y que ofrecen más información a la hora de estudiar el origen y la difusión de las regiae ibéricas es el proceso de ocupación y poblamiento del llano en algunas regiones hispanas durante el llamado periodo «post-orientalizante», caso de las comarcas centrales extremeñas. Ofrecen abundante e interesante información tanto por su riqueza material como porque han sido ampliamente estudiadas (Celestino, 2001; Rodríguez Díaz, 2004; 2007; Jiménez Ávila, 2008; 2009; 2009b). En estas regiones se desarrollaron, a partir del siglo VI a.C., unos modelos arquitectónicos de tipo palacial entre los que destaca el ya mencionado de Cancho Roano y otros ejemplos, caso del complejo monumental de La Mata de Campanario (Badajoz) (Fig. 10), ubicado a unos $25 \mathrm{~km} \mathrm{del}$ anterior. Evidentemente, aparte de la importancia de su tipología constructiva, es fundamental contextualizar estos edificios aislados vertebrando las redes de producción y circulación de objetos de lujo tanto por su región como por otros ámbitos bien distintos de la Península Ibérica9. Pero sin desatender al contenido, es el continente, es decir, la estructuración y la modulación de estos espacios, lo que más nos interesa aquí. Nos parece fundamental destacar la «sumisión» de estos edificios, en palabras de J. Jiménez, a un modelo arquitectónico preestablecido, claramente vinculado con un proceso ideológico y político que evolucionó a la par (Jiménez Ávila, 2008, 118).

Los complejos monumentales extremeños fueron creciendo y adaptándose a las nuevas necesidades partiendo de unas estructuras más simples, tripartitas y caracterizadas por un pequeño patio exterior o atrio, un corredor transversal y tres módulos longitudinales a los que se accedió desde este corredor, con el central generalmente de mayor anchura. Este módulo ha sido definido como «edificio en tridente» por el esquema que representa, y que acabamos de describir, bien apreciable en la planta de Cancho Roano B, en La Mata, en Fernão Vaz de Ourique o en Malhada das Taliscas 4 (Jiménez Ávila, 2009; Mataloto, 2008). La repetición de la estructura arquitectónica demuestra, como en el caso de las regiae ibéricas del sureste, la unidad funcional que, en el caso extremeño, ha sido explicada por

9. Muchos de estos complejos se ubican en la cuenca del Guadiana. Para la localización de los más de veinte señalados remitimos al mapa de distribución publicado por Jiménez Ávila, 2008, pág. 116. 
su condición de residencias aristocráticas de dinastías rurales que controlaron la explotación agrícola de las vegas, y que en el ibérico bien podríamos relacionar con su condición de centros de mercado regidos por autoridades político/religiosas vinculadas con el intercambio de productos y con el control de las mercancías de prestigio. Un punto importante que cabe remarcar es que los modelos extremeños fueron siendo abandonados a finales del siglo V a.C., concretamente en el momento de eclosión de las regiae ibéricas del sureste, lo que denota su vinculación directa con la desaparición de las aristocracias rurales a fines del Hierro I (llamado post-orientalizante en la región del Guadiana e Ibérico Antiguo en el sureste), por un lado, y con las intensificaciones comerciales y con la inclusión del área ibérica en los circuitos centro-mediterráneos, por otro lado.

En otros trabajos recientes se dota a los mismos complejos monumentales del suroeste de un papel de «fortines de control del territorio colonial» (Almagro, Mederos y Torres, 2008, 159), denominados «palacios rurales fortificados», como centros agrícolas de control territorial o turres, siendo comparados con estructuras fenicias como las de Abul en el estuario del río Sado (Portugal) o Toscanos (Algarrobo, Málaga), donde han sido identificadas también actividades de almacenaje, vivienda y administración (Almagro, Mederos y Torres, 2008, y, en contra de esta comparación, Jiménez Ávila, 2009, 93 ss.). El papel de estos edificios ha sido puesto en relación con los fortines rurales ibéricos (Moret, 2001; 2002), que florecieron al contacto con los elementos coloniales. Por encima de este interesantísimo debate científico sobre la distinta funcionalidad de algunos de los establecimientos paradigmáticos aludidos, cabe reseñar que en todos ellos se ha señalado un origen del modelo - tanto arquitectónico como funcional- en la zona oriental mediterránea, que fue adaptado, como es lógico, a los gustos y a las necesidades locales.

Una vez revisada la rica y abundante documentación de los complejos del suroeste, volvemos nuestra atención sobre los ejemplos ibéricos que aquí estudiamos. Los resultados de las investigaciones llevadas a cabo en los complejos monumentales occidentales nos ratifican en la importancia de atender al análisis de los módulos y los patrones metrológicos. Por ello resulta fundamental estudiar el uso de los módulos reglados y canónicos. Sobre el templo A de la Illeta dels Banyets de El Campello, sin parangón aparente en el mundo ibérico (Olcina, 2005, 150), Almagro-Gorbea y Domínguez de la Concha avanzaron que se podía interpretar como parte de un conjunto palacial (formado por los templos A y B más el almacén) en el que se llevarían a cabo las diferentes tareas de almacenaje y comercio, regidas por una autoridad a la vez política y religiosa que residía en el templo A, razón ésta por la que fue denominado como regia (Almagro-Gorbea y Domínguez, 1988-89, 365-369). El estudio de los materiales, por el contrario, ofreció datos de relevancia para interpretar el edificio como un espacio religioso o un templo, dada la cantidad de terracotas, que, por otro lado, son fundamentales para determinar y caracterizar un espacio de culto, y algunos elementos escultóricos fragmentados (Olcina, 2005, 150; Olcina, Martínez y Sala, 2009).

El templo A de la Illeta es un edificio de planta trapezoidal con fachada de $8^{\prime} 90 \mathrm{~m}$ en la que se levantan dos columnas de sección ochavada que dan paso a un espacio rectangular y alargado (el pronaos, según Llobregat). A través de la fachada, definida por su excavador como in antis, se abre una puerta por la que se accede al cuerpo central, sin cambio de nivel, que consta de tres naves. La central, más ancha, no presenta cierre como las contiguas, sino que quedaría abierta a dos cámaras divididas por un muro. De esta parte posterior u opistodomos sólo se conservaba parte del muro divisorio, aunque la restitución es bastante segura gracias a la abundante información dejada por Llobregat, y que ha sido fundamental para las reconstrucciones realizadas. Inicialmente se planteó que el templo se distribuyese en torno a un patio central (Llobregat, 1983, 250), cuestión desechada por Llobregat debido a la escasa anchura de los muros internos, que consideró, por lo tanto, medianeros. Por eso se decantó por un remate a doble vertiente recubierto con material perecedero, al no encontrar rastro alguno de tejas, tal y como se observa en alguna propuesta de reconstrucción publicada (Llobregat, 1985, Fig. 2). En cuanto a la modulación, cabe reseñar que las dimensiones de las basas correspondían con las que especialistas en arquitectura púnica, como A. Jodin, otorgaban a los ejemplos púnicos africanos (Jodin, 1975), e igualmente sucedía con el módulo de los adobes, correspondiente a un codo púnico de $0,55 \mathrm{~m}$ (Olcina, Martínez y Sala, 2009, 164).

Del edificio de la Illeta ha sido señalada recientemente una cuestión que nos parece clave y de gran interés para ayudar a su caracterización: su aislamiento, así como su orientación astronómica, con las cuatro esquinas marcando los cuatro puntos cardinales (Olcina, 2005, 153); la misma orientación ha quedado señalada por los excavadores del templo del kothon de Mozia (Nigro, 2009). Esta cuestión no hace sino remarcar el carácter «atípico» de este edificio de El Campello, que ya había sido señalado por su excavador.

Con los paralelos arquitectónicos que han sido mencionados en apartados anteriores, así como a través de los edificios señalados como precedente, y con el análisis de los materiales exhumados en el interior de este espacio, no queda duda para los investigadores de que se trata de un templo más que de una residencia palacial (Olcina, 2005, 151). Asimismo se plantea reconsiderar como regia el edificio de las Tres Hermanas de Aspe (García y Moratalla, 1998-1999, 163 182). Además, hay que tener en cuenta también la anchura de los muros $(55-58 \mathrm{~cm})$, que se corresponden con un codo estándar púnico, como podemos observar en el caso de las murallas de Carteia, de Cartagena, del Castillo de Doña Blanca o del Tossal de Manises, en estos casos en las fases pertenecientes a la segunda 


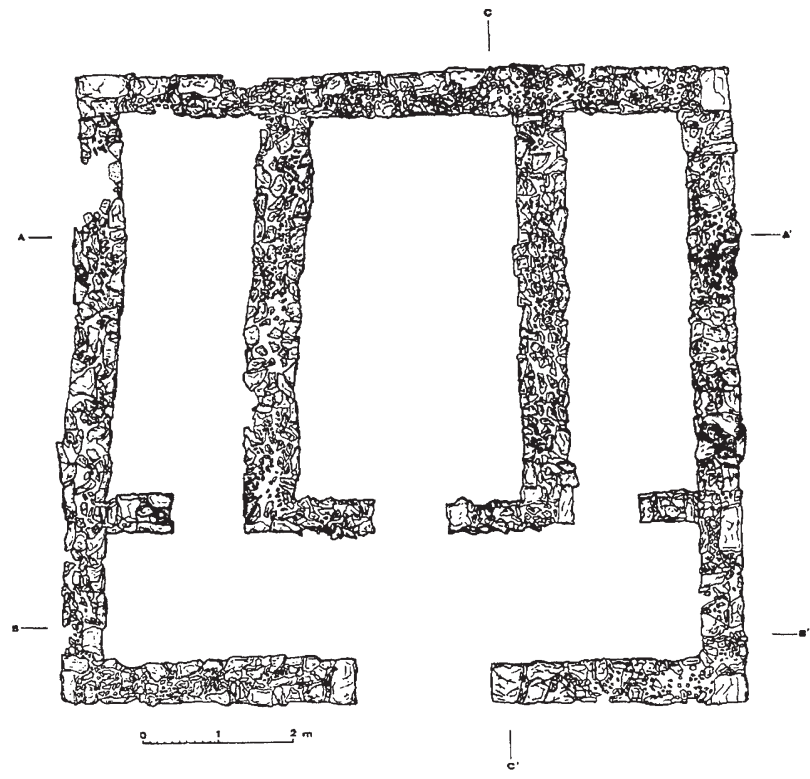

Figura 11: Planta de la llamada regia o edificio A de las Tres Hermanas (Aspe, Alicante), según García y Moratalla, 2001.

mitad del siglo III a.C. Sobre la regia de las Tres Hermanas de Aspe (Fig. 11) se han señalado unas dimensiones de unos 9 x 9 m (Moratalla Jávega, 2005, 105), correspondientes a 18 x 18 codos aproximadamente (es decir, módulos de 3 codos colocados en series de múltiplos de 3).

Ya habíamos mencionado el templo o «edificio público» hallado en la calle Ibn Chabâat de Cartago (Rakob, 1998, 29 y ss.), con una planta muy similar al templo A de la Illeta y con una función muy parecida, que se encuentra orientado este-oeste, con su parte occidental - posterior- ubicada junto al Kardo $X I I$ de la posterior colonia romana, en su confluencia con el Decumanus Maximus. En las fases más antiguas de este espacio urbano fueron hallados más de cinco mil sellos egipcios, púnicos, griegos y etruscos de arcilla, identificados como pertenecientes a un archivo de papiros. Además de estos sellos han sido exhumados numerosos elementos religiosos como terracotas y otras estatuas votivas, bronces, amuletos e incluso un depósito votivo de ánforas (fechado hacia 240 a.C. por el hallazgo de una moneda). En la última fase del edificio (principios del siglo II a.C.), éste fue reconstruido y decorado lujosamente, incluyendo la utilización de elementos decorativos y arquitectónicos de gran monumentalidad (mármoles, estucos, capiteles eólicos, etc.). De este edificio, además de su característica planta, idéntica a las que analizamos en estas páginas, destaca su papel como archivo y puede que como lugar de depósito o almacenaje de productos ${ }^{10}$ en ánforas. Una característica y una funcionalidad comercial-económico-religiosa similar a la que podemos

10. Posiblemente vino. observar en el caso de los modelos ibéricos que estamos abordando en este estudio, que comparten con el edificio cartaginés cronología y una planta bastante similar, así como en otros lugares alejados del Mediterráneo pero vinculados culturalmente con el mundo fenicio, como el templo libanés de Milk'Ashtart, con la misma función e idéntica estructura (Dunand y Duru, 1962, Figs. 10 y 17).

En el siguiente esquema se muestran los edificios analizados en el texto para simplificar y agilizar la comparativa entre sus dimensiones y su modulación, así como la superficie útil que presentan:

\begin{tabular}{|c|c|c|c|}
\hline Edificio & Dimensiones & $\begin{array}{c}\text { Ancho } \\
\text { muros }\end{array}$ & $\begin{array}{c}\text { Superficie } \\
\text { útil }\end{array}$ \\
\hline Toscanos «C» & $\begin{array}{c}10,75 \times 14 \\
\mathrm{~m}^{(*)}\end{array}$ & $0,55-0,60 \mathrm{~m}$ & $96 \mathrm{~m}^{2(* *)}$ \\
\hline $\begin{array}{c}\text { Campello, } \\
\text { templo A }\end{array}$ & $\begin{array}{c}12 \times 9,40- \\
8,50 \mathrm{~m}\end{array}$ & $0,55-0,60 \mathrm{~m}$ & $45 \mathrm{~m}^{2}$ \\
\hline $\begin{array}{c}\text { Tres } \\
\text { Hermanas }\end{array}$ & $9 \times 9,25$ & $0,58-0,60 \mathrm{~m}$ & $50 \mathrm{~m}^{2}$ \\
\hline El Chorrillo & $11 \times 9,30 \mathrm{~m}$ & $0,60 \mathrm{~m}$ & $63 \mathrm{~m}^{2}$ \\
\hline $\begin{array}{c}\text { Cancho } \\
\text { Roano A }\end{array}$ & $12 \times 9 \mathrm{~m}$ & $0,60 \mathrm{~m}$ & $70 \mathrm{~m}^{2}$ \\
\hline $\begin{array}{c}\text { Cancho } \\
\text { Roano B }\end{array}$ & $12 \times 9 \mathrm{~m}$ & $0,60 \mathrm{~m}$ & $70 \mathrm{~m}^{2}$ \\
\hline $\begin{array}{c}\text { Alarcos } \\
\text { sector IV-E }\end{array}$ & $9,90 \times 7,30$ & $0,60 \mathrm{~m}$ & $72 \mathrm{~m}^{2}$ \\
\hline
\end{tabular}

(*) distancia longitudinal aproximada, al no conocerse con exactitud el cierre al sur (Schubart, 2002, 62).

$(* *)$ superficie aproximada de la planta inferior (se le supone una superior: Arnold y Marzoli, 2009).

\section{LOS MODELOS IBÉRICOS. EVOLUCIÓN CRO- NOLÓGICA Y FUNCIONAL}

La primera estructura que vamos a comentar es la de El Chorrillo, ubicada entre los actuales términos municipales de Elda, Petrer y Sax, en la provincia de Alicante, cuya disposición se asemeja a una regia con planta tripartita, según se desprende del análisis de los restos conservados. Este espacio se ubica en la parte más elevada del cerro en el que se encuentra el yacimiento ibérico, aunque aislado del mismo. Se trata de un edificio de $9,3 \times 11 \mathrm{~m}$ (equivalente a $18 \times 21$ codos, de nuevo agrupados en múltiplos de tres) desaparecido parcialmente: se encuentra muy erosionado y consta, por lo tanto, de muy poca potencia estratigráfica. Según la planta dibujada por sus excavadores (Jover y Segura, 1995; Márquez et alii, 1997), presenta un ambiente central y dos estancias laterales. La estancia central, de mayor anchura que las laterales, mide $8 \mathrm{x}$ 3,6 m. En su interior fueron documentados materiales fechados en el siglo $\mathrm{V}$ a.C. aunque la mayor parte del conjunto se puede datar a lo largo del siglo IV a.C., con algunos materiales de finales de la centuria. El edificio se ubica en lo alto de un cabezo, emergiendo de forma individual, y se encuentra aislado y con visibilidad sobre todo el territorio circundante, controlando una 


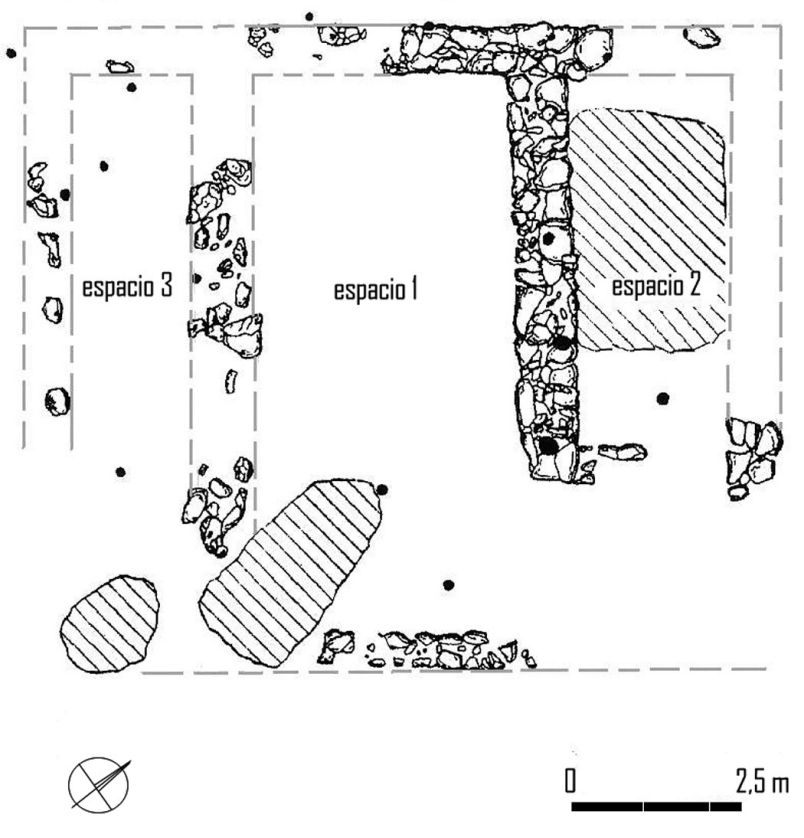

Figura 12: Planta del edificio de El Chorrillo (Elda-Petrer-Sax, Alicante), modificada a partir de Márquez et alii, 1997.

zona de vado sobre el río Vinalopó, desde su margen izquierda.

En la regia de El Chorrillo (Fig. 12) no está del todo clara su asociación con el poblado existente en la parte inferior del cerro, lo que acentúa el carácter «especial»o «singular» del edificio. En uno de los cerros próximos se halló una escultura ibérica, pero, al tratarse de un hallazgo aislado y descontextualizado, no se puede hablar de la existencia de una necrópolis. Uno de los detalles más destacados es la modulación «canónica» del edificio, de 18 × 21 codos de $0,52 \mathrm{~cm}$, una proporción bastante recurrente en este tipo de espacios «singulares», correspondiente a la repetición sistemática de un módulo (codo) de en torno a 50-55 $\mathrm{cm}$ en grupos de tres o sus múltiplos. A pesar de su mal estado de conservación se ha podido constatar en El Chorrillo la ausencia de cimentación, ya que fue erigido apoyando los muros directamente sobre la roca virgen (Márquez et alii, 1997, 328). Los excavadores del edificio subrayan la «escasez de paralelos en el ámbito ibérico» e insisten acerca de su total aislamiento y la forma en la que «emerge de forma individual en el territorio circundante» (Márquez et alii, 1997, 333). A partir de estos datos y de la planta publicada podemos plantear que nos encontramos ante una estructura de similares características a la de las Tres Hermanas de Aspe, de una misma época, con un papel destacado en lo concerniente al control del territorio y con ciertas connotaciones de tipo religioso, por su ubicación y por su estructura. La utilización de una misma modulación y una tipología idéntica nos lleva a pensar que ambos yacimientos compartieron una misma funcionalidad,

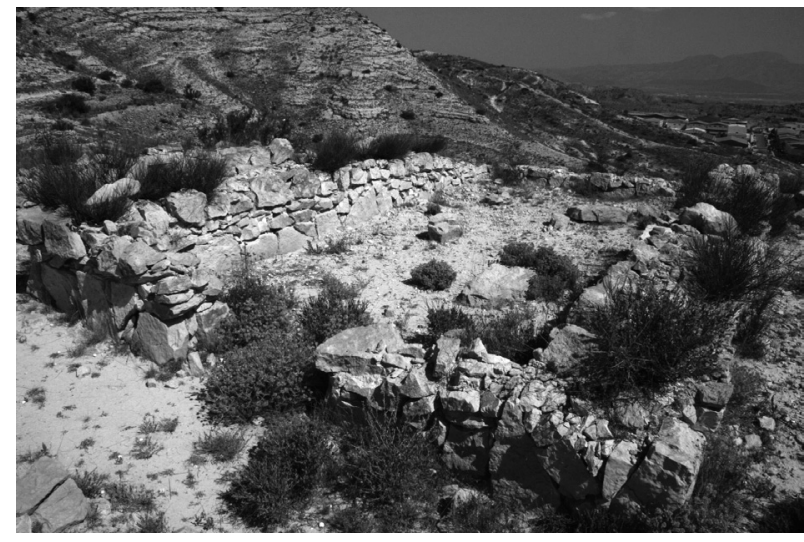

Figura 13: Vista de la nave central de la llamada regia (Edificio A) de las Tres Hermanas (Aspe, Alicante).

siendo ambos, como veremos, cabeceras de sus propios territorios.

Otro ejemplo, si bien con una interpretación algo más problemática por los escasos datos que se manejan, sería el del edificio tripartito ubicado en la cima de La Serreta de Alcoy (Grau y Moratalla, 1999; Grau Mira, 2002, 230). Aunque parece que no se trata del célebre santuario que se encontraría algo más arriba (Visedo Moltó, 1922; Llobregat, 1984), y, al haberse hallado algunos fragmentos de teja, puede que se trate de una construcción de época romana, de todas formas es interesante la planta y la forma en la que los muros están realizados, con esa suerte de engatillados y ripios rústicos (Olcina, 2005). La realización de este edificio en la parte superior del oppidum ibérico de La Serreta responde a una obra de carácter complejo que aterrazó el terreno, creando incluso un paso artificial al oeste. Toda la construcción responde a un módulo de $52 \mathrm{~cm}$ (= codo púnico) que se observa, por ejemplo, en la anchura de los muros perimetrales (no así en los dos medianeros, que dividen el espacio interior en tres). El edificio está orientado este-oeste hacia el Puig Campana (Benidorm), por donde parece que sale el sol en el equinoccio otoñal. Este hecho tuvo que ver, sin lugar a dudas, con la adscripción del sitio a ritos de tipo agrícola, vinculados con el culto a la diosa madre, algo por otro lado bastante habitual en el mundo ibérico. De todas formas es problemática la introducción del santuario de La Serreta dentro de estos modelos; los datos arqueológicos son escasos, así como las referencias. Aun así, hay que tener en cuenta que en algún caso ha sido descrito el santuario de La Serreta como «lugar de culto que responde a un modelo de tradición oriental» (Llobregat et alii, 1992, 62).

En el ya aludido ejemplo del edificio A de las Tres Hermanas (Aspe, Alicante) destaca la realización de una arquitectura de prestigio (Fig. 13), señalada desde sus primeras noticias (García y Moratalla, 1999), donde cabe señalar, además, su posición dominante, visible desde toda la Vega Baja, así como su aislamiento, encontrándose alejado, una vez más, de centros 


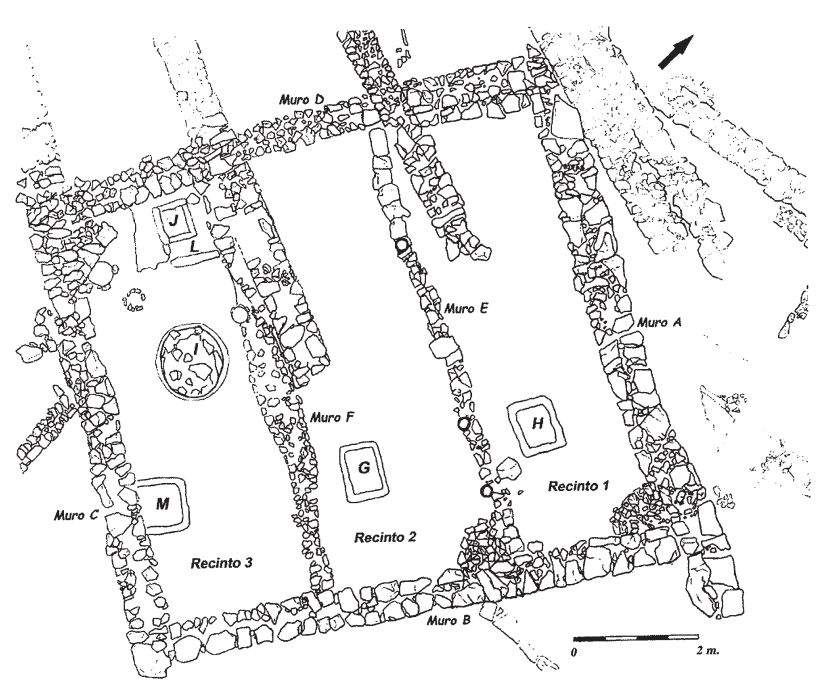

Figura 14: El edificio del sector IV-E del oppidum de Alarcos, Ciudad Real (según Fernández, 2008, 71).

poblados (Moratalla Jávega, 2005, 105). Presenta un acceso dificultoso por todas sus vertientes, con pendientes superiores al 35\% a excepción de la suroeste, donde es más tendida (25\%), estando orientada su puerta, pues, hacia el ocaso.

Ya habíamos mencionado que presenta un módulo de 9 metros de lado (que se corresponde con unos 18 codos, de nuevo con la proporción de 3 codos o múltiplos de 3 que veíamos anteriormente). Estos 9 metros de anchura del edificio son la misma medida del templo A de El Campello. Los excavadores comparan este modelo habitacional con Cancho Roano y con la planta de la Cámara de Toya, ambos espacios de clara influencia semita, así como con el templo A de la Illeta de El Campello. La comparación con estos espacios ha provocado la identificación del edificio de Aspe como una regia, es decir, la residencia de un rey sagrado, es decir, un edificio de corte palacial residencia de una jefatura.

Los materiales asociados al edificio de las Tres Hermanas de Aspe indican cierto prestigio, así como el camino de acceso empedrado y enmarcado por lajas de piedra hincadas aún visibles (Fig. 16). El edificio presenta tres naves de unos $10 \mathrm{~m}$ de profundidad (unos 18 codos) por 1,50 m de anchura (cerca de 3 codos), que equivalen de nuevo a una proporción canónica basada en el empleo de módulos de 3 codos y sus múltiplos. J. Moratalla menciona el tripartito de Aspe tratándolo de regia y comparándolo con el de La Illeta de El Campello (Moratalla, 2005). En las proximidades de esta estructura existe otra sobre la que ya hemos trabajado anteriormente, y que hemos tenido ocasión de relacionar también con un lugar de reunión (Prados Martínez, 2006, 61, fig. 16) por su característica planta y sus dimensiones.

El caso del templo A de la Illeta de El Campello es bastante particular; hay que señalar la práctica ausencia de viviendas en la superficie de la Illeta (ya señalada por Llobregat, 1993, que lo identificó con un emporion). Junto con los datos ya aportados anteriormente cabe señalar que la fachada del templo mide $8,90 \mathrm{~m}$ por $13 \mathrm{~m}$ de profundidad, y el grosor de los muros (de entre 50 y $60 \mathrm{~cm}$ ) se corresponde de nuevo con el codo que venimos mencionando a lo largo de estas páginas. Creemos oportuno señalar la existencia de un complejo alfarero de gran entidad en las proximidades de la Illeta. Allí fueron excavados durante sucesivas campañas (las últimas seis realizadas entre 1993 y 1998) varios hornos que produjeron, en más de un 95\%, grandes contenedores anfóricos (López Seguí, 2000, 246). Según los estudios de los especialistas, estos materiales tuvieron una amplia difusión, pudiendo ser embarcados en la costa alicantina para ser empleados como contenedores (probablemente del vino producido en los lagares mencionados anteriormente), en dirección a las Islas Baleares (López Seguí, 2000, 247). La posición dominante de los edificios -entre ellos el centro de redistribución- de la Illeta dels Banyets y la aparición del almacén pueden relacionarse, pues, con la instrumentalización del control del comercio, que se canalizó a través de lo que pudo ser un port of trade de la costa contestana.

Otros modelos arquitectónicos que parece que han tenido una misma funcionalidad, interpretados como centros de distribución de carácter sacro, aunque no comparten con los aquí estudiados su estructura arquitectónica, son el santuario de la Muela de Cástulo (Blázquez, 1986 y 1991; Blázquez y García Gelabert, 1994), cronológicamente más antiguo, o el santuario de Mas Castellar de Pontós (Pons, 1993; 1997) y el edificio público de Molí de Espigol (Tornabous, Lérida) ${ }^{11}$, en el que destaca el llamado «edificio A», el más espectacular del asentamiento, que presenta una estructura con una entrada también flanqueada por dos columnas y varias estancias a los lados de una habitación con un hogar central de planta rectangular (Cura y Principal, 1993; Cura, 2006). También ha sido señalada como paralelo la Cámara de Toya, si bien, al tratarse de una cámara funeraria, no la consideramos como un paralelo, aunque presente una planta similar, que ha sido

11. Para la contextualización de este edificio «A», cabe destacar que Tornabous no fue un oppidum más, desde luego; la existencia de espacios públicos, los edificios cargados de significación social y religiosa sin parangón en la zona y la preocupación constante por protegerse mediante sucesivos recintos fortificados hacen pensar que en el Molí d'Espigol residió un poder político/religioso importante, en un lugar que, como han señalado sus excavadores, pudo ser un lugar de cohesión (Cura, 2006), un meeting point diríamos hoy siguiendo la terminología anglosajona, con buenos paralelos en otras zonas ibéricas, como, por ejemplo, en la ya aludida Tallada IV de Caspe (Zaragoza), en la región ausetana al sur del Ebro. Nos parece acertada esta identificación, dado que el lugar, con ese modelo arquitectónico, pudo compartir funciones sociales y económicas por igual, sin abandonar nunca el sentido religioso propio de un espacio de redistribución comercial. 
señalada como una «trasposición a la arquitectura funeraria de una planta tradicional de la arquitectura civil ibérica» (Almagro y Domínguez, 1988-1989, 368).

Asimismo, en los últimos años se ha excavado un edificio de plan tripartito en un ámbito urbano - sector IV-E- en el oppidum de Alarcos (Ciudad Real), con una modulación canónica de 7,30 x 9,90 m, empleado fundamentalmente como almacén, aunque tiene unas características constructivas que acentúan su carácter «especial», tales como el fino estucado de las paredes internas (Fernández Rodríguez, 2008, 70). La construcción de este almacén tripartirto (Fig. 14), realizado con zócalos de mampostería y alzados de adobes, se corresponde con un cambio en la cultura material del oppidum, que se caracteriza por una mayor presencia de importaciones, concretamente de vasos griegos fechados a finales del $\mathrm{s}$. $\mathrm{V}$ y las primeras décadas del IV a.C. La construcción del edificio tripartito es coetánea a la del santuario de Alarcos y a su utilización ${ }^{12}$. En el interior del almacén, cada uno de los tres espacios presenta unas estructuras distintas. Así, en el situado más al sur (Recinto 3), aparece una mesa de trabajo, una forja, unas piletas y un hogar, elementos propios de una actividad industrial, mientras que en los otros dos (Recintos 2 y 1), junto a sendos hogares, apareció abundante cerámica ibérica y de importación, predominando los grandes contenedores destinados a almacenaje y otros vasos de menor tamaño. Todos ellos aparecieron completos bajo el derrumbe de la techumbre, y presentaban abundantes restos de cereal en su interior, además de que, por su situación, parece que estuvieron ubicados sobre estantes y que se quemaron después de caer y romperse (Fernández Rodríguez, 2008, 73). Desde luego, no se trata de un edificio convencional ni de un ámbito doméstico, tanto por lo particular de su estructura arquitectónica como por el contenido y los elementos inmuebles. Un dato de interés es que las tres habitaciones que conforman el espacio no están comunicadas entre sí, lo que lo aleja de ser interpretado como vivienda. Otros materiales que aparecieron en el interior fueron fusayolas, piedras de molino y manos de moler, que se pueden poner en relación tanto con la industria textil como con la transformación de alimentos.

\section{EL TERRITORIO DE LAS REGIAE. APROXI- MACIÓN GEOGRÁFICA}

Para caracterizar estas construcciones es fundamental atender a su ubicación espacial. Ya se conoce la importancia de la aplicación de los estudios de paisaje para explicar muchos de los procesos históricos y económicos en la Protohistoria del Mediterráneo y, en el caso

12. Los excavadores ofrecen resultados de análisis de C14 calibrado a dos sigmas que ofrecen un abanico cronológico de entre 520-380 a.C. (Fernández Rodríguez, 2008, 76). que nos ocupa, que atiende a un tipo de estructuras por lo general aisladas respecto a los centros urbanos, pero vinculadas a ellos, mucho más, pues buena parte de las propuestas que en este trabajo se realizan vienen determinadas por el estudio de la posición geográfica de los edificios, muchas veces más clarificadora que el propio análisis arquitectónico, aunque sea éste la base sobre la que se fundamenta este trabajo. Además, de cara a la adscripción cultural de las regiae ibéricas dentro de la órbita púnica hemos de tener presente, como ya hemos ido señalando a lo largo de estas páginas, la especial vinculación del territorio contestano, sobre todo en su vertiente más costera, con la isla de Ibiza, principalmente a partir de la segunda mitad del siglo IV a.C., que se corresponde históricamente con el segundo tratado romano-cartaginés (348 a.C.), a partir del que se detecta una intensificación en el comercio púnico, sobre la que volveremos más adelante en el apartado de conclusiones. Sólo entendiendo la inclusión de este territorio dentro de los circuitos económicos y culturales púnicos podemos dar respuesta a muchos de los procesos aquí referidos, fechados en época Ibérica Plena.

Aunque le damos una importancia fundamental al estudio del paisaje y entendemos éste como clave para intentar encontrar una respuesta fidedigna a la función y carácter de las regiae ibéricas, además de a otras cuestiones fundamentales, como la propia organización del poblamiento y del territorio, no ahondaremos en ello en estas páginas, principalmente porque las regiones en las que se enclavan los modelos arquitectónicos objeto de estudio han sido suficientemente estudiadas y publicadas por colegas del Departamento de la Universidad de Alicante ${ }^{13}$ a ellas debemos, además, muchas de las observaciones a este respecto aquí presentadas y que indudablemente agradecemos. Por ello nos acercaremos tan sólo a partir de una escala microespacial, teniendo en cuenta el papel que edificios como el de Aspe o el de El Chorrillo pudieron desempeñar, al estar ubicados en la cabecera de sus respectivos territorios y en las márgenes del mismo eje fluvial vertebrador del poblamiento ibérico de la zona (Moratalla Jávega, 2005).

Su posición en zonas elevadas, además, los alejan de poder ser identificados como caseríos de explotación agrícola, lo que podrían parecer por su reducido tamaño, similar al de núcleos como el Teular de Mollà en la Vall d'Albaida, o el Riu d'Agres o La Solaneta en el Alcoià (Grau Mira, 2002, 121). Además, la fecha de las regiae en el Ibérico Pleno curiosamente se corresponde con un momento de retroceso de este tipo de asentamientos agrícolas, que tuvieron mucha profusión en el Ibérico Antiguo y que no volverán a tener desarrollo hasta el siglo III a.C. Curiosamente, este retroceso en el número de granjas se corresponde con un

13. Véase, por ejemplo, al respecto: Grau Mira, 2002; 2005; Grau y Moratalla, 1999; Moratalla Jávega, 2005. 


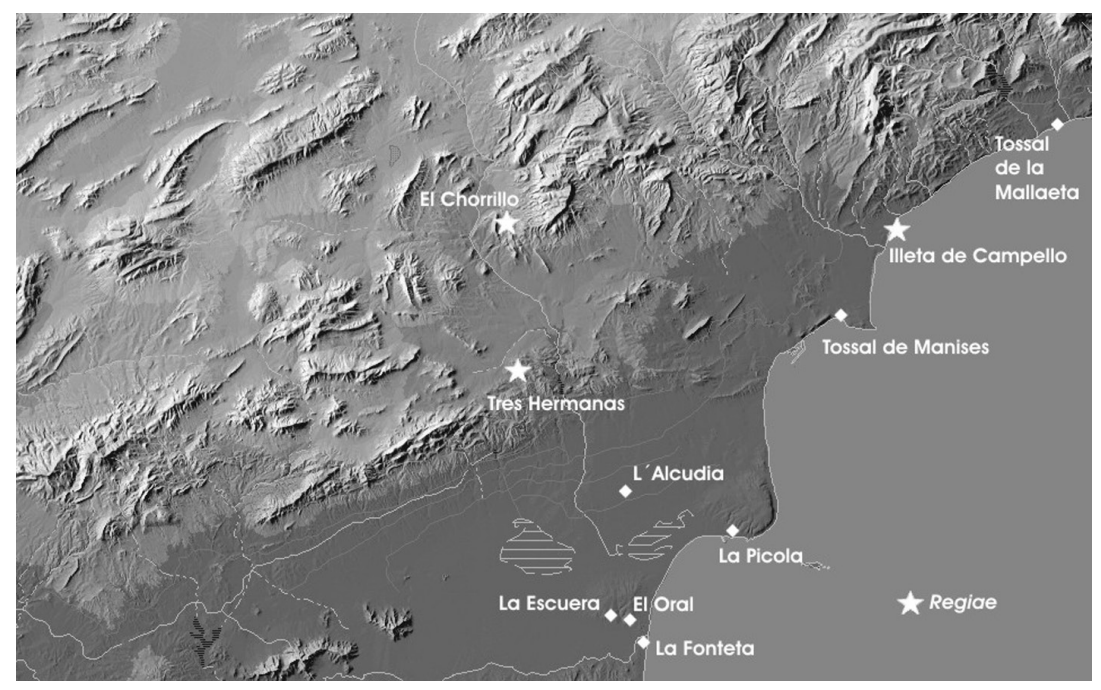

Figura 15: El área central de la Contestania Ibérica. Las estrellas señalan la ubicación de las llamadas regiae mencionadas en el texto.

momento de aumento en el número de asentamientos e incremento de la riqueza de los ajuares en las necrópolis (Sala, 2002, 294; Grau Mira, 2006, 50). Por otro lado, el tipo de planta y la estructura de los edificios de El Chorrillo o Aspe tampoco permiten una identificación con torres o atalayas defensivas, como sucede en el Perengil de Vinaroz, Castellón (Oliver, 2001), por lo que se acentúa su carácter distintivo.

Habíamos visto cómo en el caso de los edificios de Aspe resultaba fundamental destacar su ubicación, controlando las vías de comunicación entre la costa y el interior, a través del valle del Vinalopó (Fig. 15). Este tipo de edificios, de claras connotaciones religiosas, se ubicaron, por lo general, en la cabecera de los valles, abriendo y cerrando los territorios, y se encontraban a caballo entre varios de ellos, por lo que debieron compartir una misma identidad colectiva y pudieron funcionar para cohesionar la población del entorno a partir de vínculos religiosos/comerciales. $\mathrm{Su}$ principal característica, por lo tanto, debió ser la de sancionar las transacciones comerciales que se realizaron entre las distintas etnias que poblaron el territorio, funcionando, asimismo, como hitos fronterizos de alguna forma y posiblemente articulando el territorio de manera similar a lo que se ha visto en el caso de otros santuarios ibéricos, tanto en la región del sureste como en otras áreas ibéricas (Grau Mira, 2002, 21). Sobre el Chorrillo de Petrer ya habíamos planteado, además, que se ubicaba en uno de los vados del río Vinalopó, en este caso en su curso medio; aguas arriba, por lo tanto, de Aspe. Las características físicas son similares y puede que la función territorial sea la misma en ambos casos. Además, hay que tener en cuenta que ambos yacimientos enmarcaron por el norte y por el sur el valle medio del Vinalopó, poco poblado en esas fechas (desde finales del s. V y a lo largo del IV a.C.), ya que no se han podido documentar estructuras urbanas de entidad a excepción de La Alcudia de Elche, ubicada ya en el Bajo Vinalopó, que debió ejercer un papel territorial preponderante (Moratalla Jávega, 2005). En esa zona de conexión entre los valles del interior y el Bajo Vinalopó, I. Grau y J. Moratalla han señalado la existencia de vacíos demográficos o «fronteras desierto». Es en esa zona en la que se enmarcan las estructuras cuyo estudio aquí abordamos y que, además, se pueden inscribir dentro de un proceso frecuente en el sureste, como es la generalización de la construcción de santuarios periurbanos o territoriales ${ }^{14}$, que dotaron al paisaje de una estructura simbólica y, al tiempo, ejercieron un control y una coerción ideológica sobre el territorio.

Los otros ejemplos que hemos ido viendo responden a otros patrones, dada su ubicación en un enclave costero, en el caso de la Illeta dels Banyets, y al estar inmersos en entramados urbanos, como sucede también en los ejemplos de fuera del territorio contestano aludidos como Alarcos. A pesar de ello, en el caso de la Illeta también se ha señalado un vacío poblacional a su alrededor (Olcina, Martínez y Sala, 2009, 22), y se ha inscrito su posición presidiendo también otra zona de «frontera-desierto» (Llobregat, 1972, 26), como sucedía con las dos regiae del Vinalopó. Además, las tierras que circundaron la Illeta no eran aptas para el cultivo o la ganadería, pero su ubicación en el espacio liminal entre el llano y la costa la dotó de un papel destacado en el marco de las relaciones comerciales -e interétnicas-, que se refleja en la naturaleza de las construcciones que allí se desarrollaron. Sí fue un buen fondeadero y un lugar con una visibilidad destacada de la costa, sobre todo por su posición adelantada

14. Tales como El Cigarralejo de Mula, la Luz de Verdolay o La Encarnación de Caravaca, entre otros. 
frente al litora ${ }^{15}$. La especial posición geográfica del yacimiento ha generado dudas en lo concerniente a su adscripción territorial (Moratalla Jávega, 2005, 104), cuestión ésta que se ha de remarcar. Sólo los más recientes trabajos de prospección han aportado nuevos datos sobre el poblamiento de la zona, que se caracteriza por pequeños asentamientos que explotaban el mineral del hierro y que pudieron depender de la Illeta, si bien no ocuparon nunca el espacio inmediato, que estuvo despoblado, como se ha señalado, y funcionó como una suerte de frontera (Olcina, Martínez y Sala, 2009, 25).

En cualquier caso, aunque no coincidan los patrones geográficos, las funciones son similares, como lo fueron también los materiales que aparecieron en su interior o las estructuras arquitectónicas, como hemos tenido ocasión de ver. Estas razones son las que nos dan pie a emplazarlos en una misma escala, recurriendo a la tipificación arquitectónica y a su pertenencia a un mismo sistema arquitectónico, como veremos a continuación, para su clasificación e interpretación cultural.

\section{UNA PROPUESTA DE CARACTERIZACIÓN: CONSIDERACIONES FINALES}

Tras este recorrido, arribamos finalmente al apartado de conclusiones, en el que, lógicamente, el lector nos exigirá tomar partido por una de las distintas hipótesis aquí desarrolladas o, al menos, intentar crear una nueva bien argumentada y defendida. La realidad es que la práctica totalidad de las ideas, tesis y adscripciones que de este tipo de edificios tripartitos aquí han sido referidas, tienen muchos puntos que, a nuestro parecer, son acertados, como no podía ser de otra manera, habiendo sido propuestas por autoridades de indudable solvencia científica y buenos conocedores de la materia. Sí queremos empezar diciendo que, para nosotros, no es correcto definir estos espacios como regiae, si como tal entendemos un palacio o espacio residencial de un príncipe o cualquier autoridad monárquica. No lo entendemos así para el mundo ibérico, aunque sí podemos entender y emplear ese concepto -y así lo hemos hecho- para definir un lugar en el que una autoridad de corte sagrado, pero sobre todo administrativo/comercial, desarrolló sus competencias, pudiendo residir en otro espacio contiguo o no (como en el caso de la llamada «vivienda del cura» de la Illeta dels Banyets).

Consideramos estos espacios tremendamente recurrentes para desarrollar una arquitectura tipificada, que se repitió constantemente debido a su funcionalidad. Hoy en día repetimos arquitecturas funcionales con profusión, variando detalles que pueden conformar

15. Por lo que ha sido relacionado con el Santuario de Illa Plana (Ibiza) o con el de Escombreras (Cartagena). distintos estilos pero sin mutar la esencia de la construcción, es decir, sin dejarlos «vacíos» de significado. Así, por citar un ejemplo, las iglesias y monasterios ubicados en rutas de peregrinación, como la que llevaba a Santiago de Compostela, fueron diseñados invariablemente con deambulatorios y girola para permitir el trasiego de los peregrinos por el interior sin incomodar a aquellos que seguían el culto religioso. Así, contamos con una repetición de un modelo «funcional» desde los primeros edificios románicos del Camino, pasando por los de estilo gótico y renacentista, hasta llegar a las capillas edificadas en los últimos años. Evidentemente, el peso de la tradición también tiene fuerza, tanta o más que la funcionalidad manifiesta. Pero no olvidemos que esta misma tradición se hizo patente en las regiae ibéricas, herederas directas de un modelo de génesis y tradición orientalizante.

Cabe destacar también cierto vínculo con los espacios de reunión definidos como meeting point por la literatura científica anglosajona. La propia ubicación liminal o fronteriza de los edificios provocó que se transformasen en lugares de reunión, donde, aparte de realizar trueques y transacciones comerciales o pactos de compra-venta, etc., se pudieron desarrollar relaciones inter-grupales o comunales, y convenios o alianzas de distinta índole por parte de los miembros de las dinastías clientelares. En otro trabajo publicado en esta misma revista hicimos hincapié en este sentido cuando abordamos el estudio de las estructuras arquitectónicas que definimos como «dependencias sacras», que se configuraban con un espacio rectangular con bancos corridos y hogares y unas pequeñas sacristías en las que se almacenaban los objetos litúrgicos empleados en los cenáculos. Como tal entendíamos estructuras como Montemolín D, la vivienda III-J de El Oral, el departamento 1 del Castellet de Bernabé, el edificio B de las Tres Hermanas de Aspe o la Tallada IV (Prados Martínez, 2006), y entendemos otras no recogidas en su momento, como el sector 11/3 de Els Vilars de Arbeca, en Lérida (G.I.P., 2005, 659, Fig.4) o la fase IV del santuario de Castro Marim, en la desembocadura del Guadiana (Arruda et alii, 2009, 85, Fig. 4).

La estructura interna y el «mobiliario» compuesto de bancos y altares de estos espacios domésticos denotaban una funcionalidad clara como ámbito de reunión, que no lo parece tanto en el caso que nos ocupa. Aquí, la presencia de elementos ponderales en alguno de los espacios tripartitos, la posibilidad de la existencia de cubiertas planas y terraza para la celebración de algún tipo de ritos o «sanciones» al aire libre, denotan una naturaleza distinta, al igual que su natural aislamiento y su posición geográfica dominante o presidiendo espacios de frontera o de vacío demográfico. Por ello, este tipo de construcciones se aproxima mucho al papel de los santuarios extraurbanos ibéricos, y así han sido definidos en ocasiones (Moneo, 2003; Olcina, 2005, 151 y nota 9). Su estructura tripartita sin podio los acercan, por otro lado, a los centros de mercado regidos por autoridades sacras del mundo 


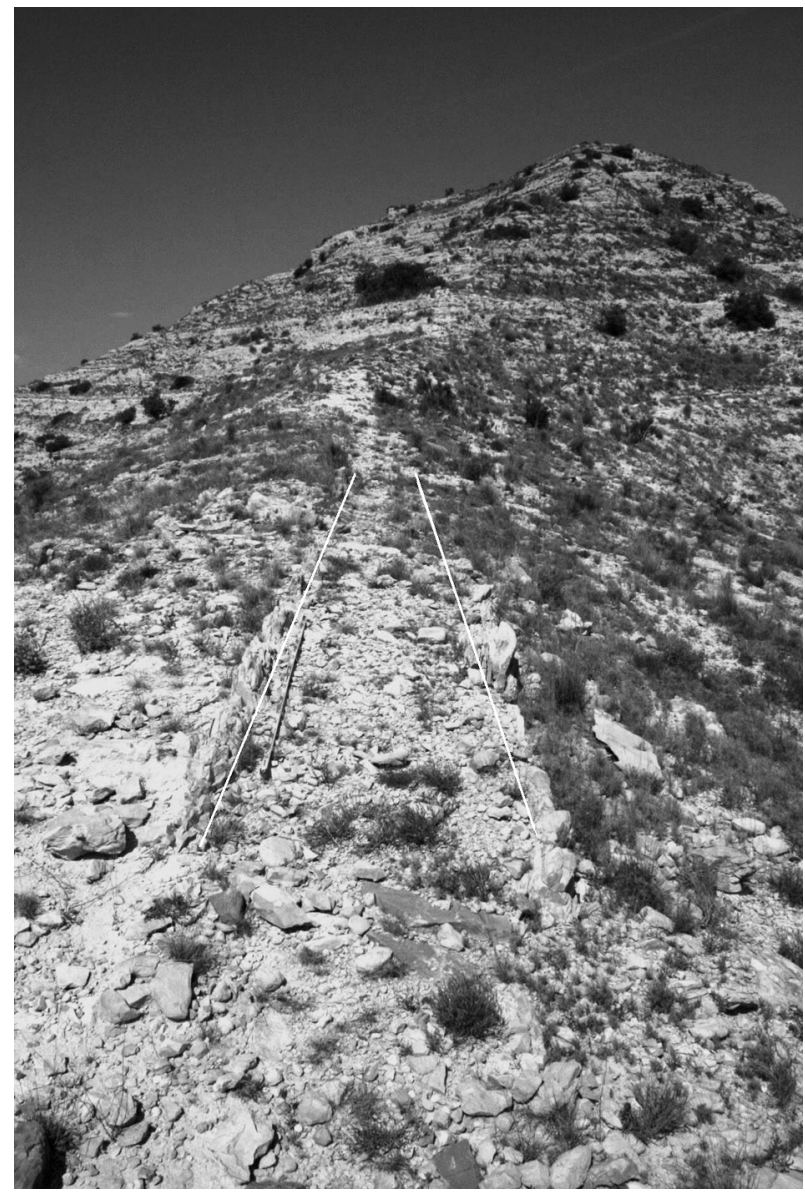

Figura 16: Camino de acceso al edificio A de las Tres Hermanas de Aspe (Alicante). Las líneas marcan la anchura delimitada por las piedras hincadas.

fenicio-púnico, como hemos visto, e, igualmente, los materiales que aparecen en su interior. Desechamos, dada la ausencia significativa de contenedores, un papel principal de almacenaje, debido, asimismo, a su aislamiento y desprotección, contando con que su propia ubicación física no sería la más adecuada para esta función. Sí cabe reseñar la existencia de caminos cuidados e incluso, como en el caso de Aspe, ritualizados en algún modo (recordemos que el acceso a la regia de las Tres Hermanas se realiza por un camino enmarcado por piedras clavadas que de alguna forma lo sacralizan, visibles en la figura 16).

Las distintas connotaciones referidas a los edificios ubicados en el ámbito ibérico (fechados entre los siglos V y III a.C.) se pueden enumerar, a modo de resumen, en estas características principales:

a) Existencia de plantas tripartitas con la nave central más ancha. Cubiertas planas.

b) Ubicación en zonas liminales, con vacíos demográficos alrededor.

c) Presencia de ponderales; quizás platillos de balanza o similares.

d) Se localizan algunos objetos rituales (telares) aunque no de culto. No hay exvotos. e) Presencia de vajilla fina relacionada con la ingesta de vino.

f) Escasa presencia de contenedores, salvo alguno para autoconsumo.

g) No se constatan favissae o bothroi, altares, hogares u otros elementos similares.

h) No se detectan destrucciones violentas o saqueos. Son abandonados y no hay constancia de perduración de las actividades tras la conquista romana, como en otros santuarios ibéricos.

Así pues, nos encontramos ante unas estructuras complejas, ubicadas en ámbitos periurbanos que abren y cierran, desde el punto de vista ideológico, el territorio. Según esta visión, estas construcciones tendrían un importante papel en el desarrollo de las identidades colectivas. En esta especie de santuarios extraurbanos se realizarían transacciones comerciales entre grupos distintos, o entre los diferentes núcleos de población que habitasen en el entorno. Pudieron funcionar como elementos señalizadores del paisaje $\mathrm{y}$, al mismo tiempo, como memoriales que mantuvieron la tradición. Se trataría, pues, de espacios de confín fuera de la ciudad. No se trata de estructuras residenciales, tampoco de templos en sí, entendidos como moradas de la divinidad, de ahí que se encuentren más cerca de ser interpretados como santuarios, aunque les falten también elementos en este sentido, como se ha visto en las características enumeradas anteriormente.

Desde el análisis tipológico cabe señalar que los edificios tripartitos forman parte, pues, de un «sistema» o «estilo» arquitectónico ${ }^{16}$, si concebimos el estilo arquitectónico como un conjunto de rasgos estructurales y decorativos que, con ciertas variaciones, como las que hemos ido viendo, se repiten dentro de una época dada o un espacio geográfico concreto. Estos sistemas se pueden observar bien en los edificios de carácter sobresaliente, como los denomina Kauffman, o en aquellos cuya funcionalidad y utilidad para la comunidad es muy elevada. Ambos tipos de edificios serán considerados la encarnación más pura de un estilo determinado (Kauffman, 1974, 97). Otra cuestión son las formas, los detalles. Formas y sistemas arquitectónicos se hacen antagónicos cuando las formas de un estilo o sistema anterior reaparecen en otro posterior porque ha surgido un renovado interés hacia ellas. Por ello, a veces tenemos la sensación, al analizar los distintos edificios, de que algo «no encaja». Las formas reaparecen; los sistemas, $\mathrm{no}^{17}$. El caso es que esta sensación de «revivalismo» no aparece en el aná-

16. Difícil de etiquetar, aunque convencionalmente se haya denominado «oriental» u «orientalizante», o, más genéricamente y de forma más ambigua, «mediterráneo».

17. Por ejemplo, las formas clásicas griegas se han empleado sucesivamente a lo largo de la historia, pero nunca se volvió a estructurar las construcciones a la manera griega. 
lisis de los edificios tripartitos denominados regiae en el ámbito ibérico, ni siquiera cuando los comparamos con los del ámbito fenicio-púnico, puesto que forman parte del mismo sistema.

La cuestión de la etnicidad y de las relaciones interétnicas es de una gran complejidad, por lo que no vamos a entrar en ello con detalle, aunque son fundamentales a la hora de estudiar los santuarios extraurbanos ibéricos. Las «culturas arqueológicas» y las «culturas arquitectónicas» no son sino compendios descriptivos de patrones de variación espacial de materiales arqueológicos o de modelos constructivos, y, por ello, pueden resultar artificiosas a la hora de definir grupos étnicos. No se pueden emplear criterios «objetivos» como los de «raza» o «lengua» para definir la etnicidad, porque ella depende, en última instancia, de sentimientos subjetivos de pertenencia a un grupo, que, además, pueden variar con el paso del tiempo y, especialmente, a través del contacto con otros grupos. Aunque la cultura material, donde queda enmarcada la arquitectura, se emplee para simbolizar diferentes aspectos de la identidad social, no sirve para señalar la identidad étnica, y las regiae tripartitas tampoco, dados además su carácter aglutinador y su amplia perduración cultural.

Evidentemente, la temprana presencia fenicia en el territorio contestano explica la adopción de muchos de los modelos arquitectónicos orientales por parte de los iberos, muchas veces desde fechas bastante tempranas (Bendala, 2001, 2003, 2005; Abad y Sala, 1993; 2001, Sala, 2005). Los especialistas señalan que la primera arquitectura ibérica en el área de estudio tuvo su origen, sin lugar a dudas, en la arquitectura fenicia de los siglos VIII y VII a.C. (Sala, 2002; 2005), con analogías tanto en los asentamientos fenicios del Bajo Segura (González Prats, 2001) como en otros ámbitos, caso del valle del Guadalquivir. Incluso el yacimiento de El Oral, auténtico paradigma arquitectónico y urbanístico, pudo estar fundado originariamente por la población residual fenopúnica de La Fonteta, que sufrió un proceso de mestizaje/hibridación con la propia de la zona (Abad y Sala, 2009, 510), como se aprecia en el siguiente cuadro:

Tartesios / bronce levantino + sustrato fenicio / orientalizante $\rightarrow$ Iberos contestanos

Iberos contestanos + adstratos púnicos $\rightarrow$ sociedad híbrida* (contestanos del s. III a.C.)

*más apreciable en la zona costera que en el interior

Sí nos parece oportuno hacer hincapié en una cuestión recientemente señalada por el profesor A. Domínguez; se trata de la presencia púnica (no de la fenicia anterior bien atestiguada, como se ha visto) en los territorios del sureste con anterioridad a época bárquida -segunda mitad del s. III a.C.- (enmarcada, pues, entre los siglos VI y III a.C.). En ocasiones, como señala el autor, ha sido confundido el elenco material como cartaginés, cuando no es sino la evolución del repertorio fenicio arcaico que se maneja en la zona desde, al menos, finales del siglo VIII a.C. (Domínguez Monedero, 2006). Es discutible la presencia cartaginesa en la zona (Grau Mira, 2006) con anterioridad a la segunda mitad del siglo III a.C., aunque, por otro lado, los indicios nos parecen suficientes como para defender una intensificación de la presencia púnica en el territorio contestano sobre todo a partir del 348 a.C., fecha del segundo tratado romano-cartaginés (Polibio III, 24, 2-4). A pesar de que no conviene emplear este tratado comercial para definir o delimitar áreas de dominio en la península (sobre todo teniendo en cuenta los problemas de ubicación de Mastia, centro en la actualidad de un interesante debate científico entre distintos investigadores), sí nos parece importante remarcar cómo esta fecha coincide con la proliferación en la región de numerosos elementos arqueológicos que se pueden catalogar como púnicos.

Entre estos elementos destaca la presencia de sepulcros «especiales» ${ }^{18}$ en algunas de las necrópolis ibéricas contestanas más conocidas, como La Albufereta o Cabezo Lucero, la aparición de monumentos funerarios de tipo punicizante (Prados Martínez, 2005), la construcción de torres de control del litoral y de los valles fluviales que se abrieron a la costa (Díes Cusí, 1990; 1992; Sala, 2006), la «arquitectonización» de los santuarios (Ruiz de Arbulo, 2000; Ramallo, 2000) y la aparición de elementos de culto de tipo centromediterráneo, como los pebeteros en forma de cabeza femenina, vinculados a la proliferación del culto de Deméter-Koré (Blech, 1998, 172; Sala, 2002, 297), además de otras cuestiones importantes, como la perduración púnica tras la conquista romana, perceptible en algunos detalles como las decoraciones de los vasos cerámicos del estilo Elche-Archena o en las inscripciones religiosas del santuario de la Cueva Negra de Fortuna (Murcia), etc.

Desde el punto de vista arquitectónico, cada vez son más evidentes los datos que aluden a la amplia difusión de una arquitectura de corte helenístico, pero de estilo púnico (y aportada por los púnicos), en los ambientes ibéricos (Fig. 17), sobre todo en las regiones costeras mediterráneas, con mayor incidencia en el tercio meridional pero con cierto impacto en las áreas septentrionales, cada vez más notorio (Moret, 2006, 218). El estudio de esta cuestión puede llegar a explicar muchos de los procesos formativos y evolutivos de las sociedades ibéricas, que compartieron con las púnicas rasgos culturales y patrones sociales

18. Con «especiales» nos referimos a la presencia de tumbas generalmente masculinas que no presentan elementos de ajuar típicamente ibéricos como el armamento, y sí, por el contrario, monedas púnicas acuñadas en Ibiza en tumbas sin señalización exterior, elementos de pasta vítrea, escarabeos, braserillos o huevos de avestruz, propios del repertorio funerario púnico. 


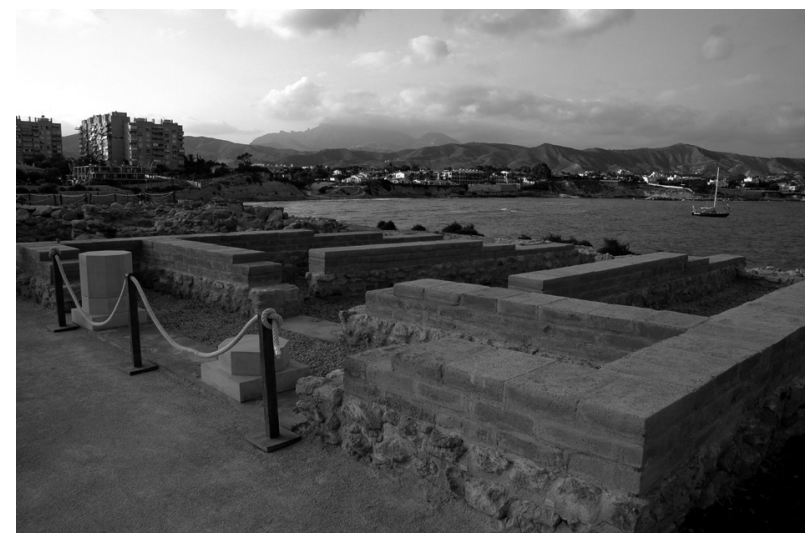

Figura 17: El templo A de la Illeta dels Banyets (El Campello, Alicante) en la actualidad, tras su musealización.

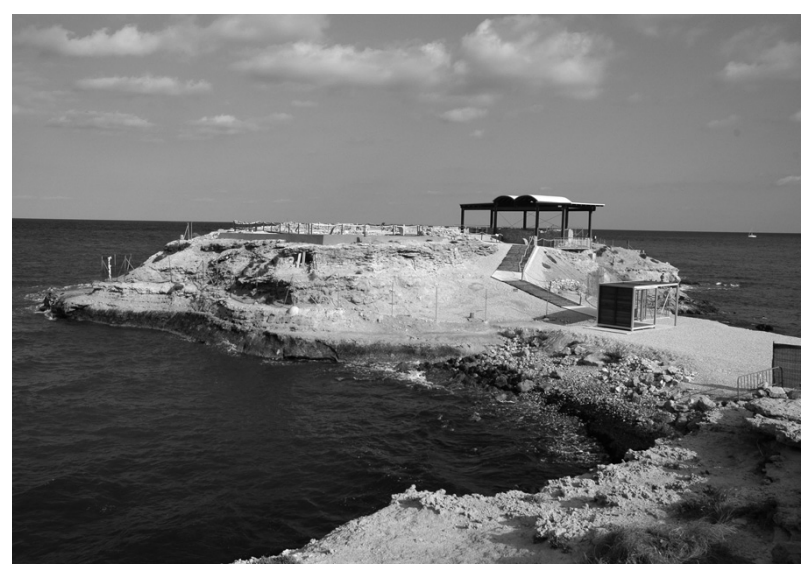

Figura 18: La Illeta dels Banyets (El Campello, Alicante) desde el norte.

desde fechas remotas (Prados Martínez, 2007), ya incluso en el momento de formación de la propia cultura ibérica allá por el siglo VI a.C., como hemos visto, por ejemplo, en el foco de la desembocadura del río Segura.

Creemos que las propuestas aquí realizadas pueden llegar a enriquecer el valor como referencia que debe tener la edilicia púnica, lo que tendrá consecuencias para un mejor entendimiento de la tradición arquitectónica ibérica. Los modelos arquitectónicos púnicos, así como los módulos constructivos empleados, son los que tuvieron una mayor difusión en el mundo indígena, y el cada vez mejor conocimiento de los primeros redunda, sin lugar a dudas, en una mejor comprensión de los últimos (Fig. 18).

Prof. Dr. Fernando Prados Martínez

Área de Arqueología

Dpto. Prehistoria, Arqueología, $\mathrm{H}^{\mathrm{a}}$ Antigua,

Filología Griega y Filología Latina

Facultad de Filosofía y Letras

Universidad de Alicante

03080 Alicante

fernando.prados@ua.es

\section{BIBLIOGRAFÍA}

ABAD CASAL, L. y SALA SELLÉS, F., 1993: El poblado ibérico de El Oral (San Fulgencio, Alicante), Valencia.

ABAD CASAL, L. y SALA SELLÉS, F., 2001: Poblamiento ibérico en el Bajo Segura. El Oral II y La Escuera, Madrid.

ABAD CASAL, L., SALA SELLÉS, F. y GRAU MIRA, I. (eds.), 2005: La Contestania Ibérica, treinta años después, Alicante.

ALMAGRO-GORBEA, M., 1996: Ideología y poder en Tartessos y el Mundo Ibérico, Madrid.

ALMAGRO-GORBEA, M., 2009: «Palacios fortificados fenicios y tartésicos. Aportación a la arquitectura y a la sociedad orientalizantes en la Península Ibérica», Homenaje a Michael Blech, Boletín de la Asociación Española de Amigos de la Arqueología, 45, 55-78.

ALMAGRO-GORBEA, M. y DOMÍNGUEZ DE LA CONCHA, A., 1988-1989: «El palacio de Cancho Roano y sus paralelos arquitectónicos y funcionales», Zephyrus, 41-42, 339-382.

ALMAGRO-GORBEA, M., DOMÍNGUEZ DE LA CONCHA, A. y LÓPEZ AMBITE, F., 1990: «Cancho Roano. Un palacio Orientalizante en la Península Ibérica», $M a$ drider Mitteilungen, 31, 251-308.

ALMAGRO-GORBEA, M., MEDEROS MARTÍN, A. y TORRES ORTIZ, M., 2008: «El territorio de Medellín en los siglos VI-V a.C.», en J. JIMÉNEZ ÁVILA (ed.), Sidereum Ana I. El río Guadiana en época post-orientalizante, Anejos de AEspA XLVI, 149-175.

ALMAGRO-GORBEA, M. y MONEO, T., 2000: Santuarios urbanos en el mundo ibérico, Madrid.

ALMAGRO-GORBEA, M. y TORRES ORTIZ, M., 2007: «Las fortificaciones tartésicas en el Suroeste peninsular», en L. BERROCAL y P. MORET (eds.), Paisajes Fortificados de la Edad del Hierro, Madrid, 35-55.

ÁLVAREZ GARCÍA, N., 1997: «El almacén del Templo A: aproximación a espacios construidos especializados y su significación socioeconómica», en M. OLCINA (ed.), La Illeta dels Banyets (El Campello, Alicante). Estudios de la Edad del Bronce y Época Ibérica, Alicante, 133-174.

ARNOLD, F. y MARZOLI, D., 2009: «Toscanos, Morro de Mezquitilla und Las Chorreras im 8. und 7. Jh. v. Chr. Siedlungsstruktur und Wohnhaustypologie», en S. HELAS y D. MARZOLI (eds.), Phönizisches und punisches Städtewesen, Mainz, 437-460.

ARRUDA, A.M., CARRETERO, P.A., TEIXEIRA, V., SOUSA, E., BARGAO, P. LOURENÇO, P. y OLIVEIRA, C.F., 2009: «Castro Marim: un santuario en la desembocadura del Guadiana», Santuarios, oppida y ciudades: arquitectura sacra en el origen y desarrollo urbano del mediterráneo occidental, IV Simposio de Arqueología de Mérida, 79-88.

AUBET SEMMLER, Ma . E., 1994: Tiro y las colonias fenicias de Occidente, Barcelona.

AUBET SEMMLER, M ${ }^{\text {a }}$.E., 1995: «El comercio fenicio en Occidente», I Fenici ieri oggi domani, Roma, 227-244. 
AUBET SEMMLER, Ma.E., 2000: «Arquitectura colonial e intercambio», en A. GONZÁLEZ (ed.), Fenicios y Territorio, Actas del II Seminario Internacional sobre Temas Fenicios (Guardamar del Segura), Alicante, 13-45.

BENDALA GALÁN, M., 2001: «Presentación», en D. RUIZ MATA y S. CELESTINO (eds.) Arquitectura oriental y orientalizante en la Península Ibérica, Madrid, s/p.

BENDALA GALÁN, M., 2003: «La influencia feniciopúnica en Alicante y su ámbito geográfico y cultural», Las ciudades y los campos de Alicante en Época Romana, Canelobre, 48, 21-33.

BENDALA GALÁN, M., 2005: «La Contestania Ibérica y el Mundo Púnico», La Contestania Ibérica, treinta años después, Alicante, 37-52.

BENDALA GALÁN, M., 2006: «Hispania/España: un Oriente en Occidente», Homenaje a D. Vicente Viñas y a Dña. Rosario Lucas Pellicer, Boletín de la Asociación Española de amigos de la Arqueología, 44, 369-385.

BENDALA GALÁN, M., 2010: «Baelo Claudia y su personalidad ciudadana y urbana: diálogo desde el estudio y la amistad», Pallas, 82, Ab Aquitania in Hispaniam, Mélanges d'histoire et d'archéologie offerts à Pierre Sillières, 465-482.

BLÁZQUEZ MARTÍNEZ, J. M., 1986: «La colonización fenicia en la Alta Andalucía (Oretania). Siglos VIII-VI a.C.», Rivista di Studi Fenici, XIV: 1, 53-80.

BLÁZQUEZ MARTÍNEZ, J. M. (ed.), 1991: Religiones en la España Antigua, Madrid.

BLÁZQUEZ MARTÍNEZ, J. M. y GARCÍA GELABERT, M. P., 1994: Cástulo, ciudad ibero-romana, Madrid.

BLECH, M., 1998: «Terracotas ibéricas», Los Iberos. Príncipes de Occidente, Barcelona, 172-173.

BONET ROSADO, H., 1995a: «Lugares de culto y ritos de influencia púnica en la Edetania Ibérica (Valencia, España)», III Congrès International des Études Phéniciennes et Puniques (Tunis, 1991), Vol. II, Túnez, 175-186.

BONET ROSADO, H., 1995b: El Tossal de Sant Miquel de Lliria: la antigua Edeta y su territorio, Valencia.

BONET ROSADO, H. y MATA PARREÑO, C., 1997: «Lugares de culto edetanos. Propuesta de definición», Espacios y lugares cultuales en el mundo ibérico, Quaderns de Prehistoria i Arqueología de Castelló, 18, 115-146.

BONET ROSADO, H. y MATA PARREÑO, C., 2001: «Organización del territorio y poblamiento en el País Valenciano entre los siglos VII al II a.C.», Entre Celtas e Iberos. Las poblaciones protohistóricas de las Galias e Hispania, Madrid, 175-186.

BRAEMER, F., 1982: L'architecture domestique du Levant à l'Âge du Fer, París.

BRANDI, C., 1967: De Struttura e Architettura, Turín.

CELESTINO PÉREZ, S., 1997: "Santuarios, centros comerciales y paisajes sacros», Espacios y lugares cultuales en el mundo ibérico, Quaderns de Prehistoria $i$ Arqueología de Castelló, 18, 359-385.

CELESTINO PÉREZ, S., 2001: Cancho Roano, Madrid.

CELESTINO PÉREZ, S. y JIMÉNEZ ÁVILA, F. J., 1993: El Palacio-Santuario de Cancho Roano IV. El Sector Norte, Badajoz.
CELESTINO PÉREZ, S. y JIMÉNEZ ÁVILA, F. J., 1996: El Palacio-Santuario de Cancho Roano V. El Sector Oeste, Madrid.

COSTA, B. y FERNÁNDEZ J. H. (eds.), 2000: Santuarios Fenicio-Púnicos en Iberia y su influencia en los cultos indígenas, XIV Jornadas de Arqueología fenicio-púnica, Ibiza.

CURA, M., 2006: El Moli d'Espigol (Tornabous, Urgell). Excavacions Arqueologiques 1987-1992, Monografies 7, Barcelona.

CURA, M. y PRINCIPAL, J., 1993: «El Molí de Espígol (Tornabous): noves constatacions arqueològiques i noves propostes interpretatives entorn al mon pre-romà», Laietània, 8, 61-84.

DÍES CUSÍ, E., 1990: «Viabilidad y finalidad de un sistema de torres de vigilancia en la Ibiza púnica», Saguntum, 23, 213-224.

DÍES CUSÍ, E., 1992: «Funcionalidad de las torres en las fortificaciones del Camp del Túria (València): defensa, vigilancia y señales», Simposi Internacional d'Arqueologia Ibèrica. Fortificacions. La problemàtica de l'Ibèric Ple: segles IV-III a.C., Manresa, 171-178.

DÍES CUSÍ, E., 2001: «La influencia de la arquitectura fenicia en las arquitecturas indígenas de la Península Ibérica», en D. RUIZ MATA y S. CELESTINO (eds), Arquitectura Oriental y Orientalizante en la Península Ibérica, Madrid, 69-122.

DOCTER, R. F. 1997: Archaische Amphoren aus Karthago und Toscanos. Fundspektrum und Formenentwicklung. Ein Beitrag zur phönizischen Wirtschaftsgeschichte mit Beiträgen von M. B. Annis - L. Jacobs - G. H. J. M. Blessing, Ámsterdam.

DOMÍNGUEZ MONEDERO, A. J., 1997: «Los lugares de culto en el mundo ibérico: espacio religioso y sociedad», Espacios y lugares cultuales en el mundo ibérico, Quaderns de Prehistoria i Arqueología de Castelló, 18, 391-404.

DOMÍNGUEZ MONEDERO, A. J., 2006: «¿Cartago en Iberia? Algunas observaciones sobre el papel de la Cartago prebárquida en la península Ibérica», Homenaje a D. Vicente Viñas y a Dña. Rosario Lucas Pellicer, Boletín de la Asociación Española de amigos de la Arqueología, 44, 181-200.

DUNAND, M. y DURU, R., 1962: Oumn el'AmEd. Une ville de l'époque hellénistique aux échelles de Tyr. Études et Documents d'Archéologie, IV, París.

FANTAR, M. H., 1984: Kerkouane, cité punique du Cap Bon (Tunisie), Vol. I, Túnez.

FANTAR, M. H., 1998: Kerkouane. Cité punique au pays berbère de Tamezrat, Túnez.

FERNÁNDEZ RODRÍGUEZ, M. D. M., 2008: «El oppidum de Alarcos en los siglos VI-V a.C.», en J. JIMÉNEZ ÁVILA (ed.), Sidereum Ana I. El río Guadiana en época post-orientalizante. Anejos de AEspA XLVI, 61-79.

GAILLEDRAT, E., 2007: «Architecture et urbanisme des Phases I-III (v.725-600 av.J.-C.)», en P. ROUILLARD, E. GAILLEDRAT y F. SALA (eds.), L'établissement protohistorique de La Fonteta, Madrid, 99-126. 
GARCÍA GANDÍA, J. R. y MORATALLA JÁVEGA, J., 1999: «Un primer avance sobre un templo de arquitectura de prestigio ibérica: las Tres Hermanas (Aspe, Alicante)», Revista del Vinalopó, 2, 151-172.

GARCÍA GANDÍA, J. R. y MORATALLA JÁVEGA, J., 1998-1999: «Nuevos datos sobre arquitectura de prestigio ibérica: la Regia de las Tres Hermanas (Aspe, Alicante)», Lucentum, XVII-XVIII, 163-182.

GARCÍA HUERTA, R. y RODRÍGUEZ GONZÁLEZ, D. (coords.), 2009: Sistemas de almacenamiento entre los pueblos prerromanos peninsulares, Cuenca.

GONZÁLEZ PRATS, A., 2001: «Arquitectura orientalizante en el Levante peninsular», en D. RUIZ MATA y S. CELESTINO (eds.), Arquitectura oriental y orientalizante en la Península Ibérica, Madrid, 173-192.

GRACIA, F., MUNILLA, G. y GARCÍA, E., 1997: «Estructura social, ideología y economía en las prácticas religiosas privadas o públicas en poblado», Espacios y lugares cultuales en el mundo ibérico, Quaderns de Prehistoria i Arqueología de Castelló, 18, 443-460.

GRAU MIRA, I., 2002: La organización del territorio en el área central de la Contestania Ibérica, Alicante.

GRAU MIRA, I., 2005: «El territorio septentrional de la Contestania», La Contestania Ibérica, treinta años después, Alicante, 73-90.

GRAU MIRA, I., 2006: «El territorio oriental de Iberia en época de los bárquidas», Rivista di Studi Fenici, XXXII, 2, 2004, 49-69.

GRAU MIRA, I. y MORATALLA JÁVEGA, J., 1999: «Espacios de control y zonas de transición en el área central de la Contestania ibérica», Recerques del Museu d'Alcoi, 9, 179-202.

G.I.P.-GRUP D'INVESTIGACIÓ PREHISTÒRICA, 2005: «Dos hogares orientalizantes de la Fortaleza de Els Vilars (Arbeca, Lleida)», en S. CELESTINO y J. JIMÉNEZ (eds.), El Periodo Orientalizante, Vol. 1, Anejos de AEspA XXXV, 651-667

GUSI, F., 1997: «Lugares sagrados, divinidades, cultos y rituales en el Levante de Iberia», Espacios y lugares cultuales en el mundo ibérico, Quaderns de Prehistoria $i$ Arqueología de Castelló, 18, 171-209.

HELAS, S. y MARZOLI, D. (eds.), 2009: Phönizisches und punisches Städtewesen, Mainz.

JIMÉNEZ ÁVILA, J., 2008: «El final del Hierro Antiguo en el Guadiana Medio», en J. JIMÉNEZ ÁVILA (ed.), Sidereum Ana I. El río Guadiana en época post-orientalizante, Anejos de AEspA XLVI, 101-134.

JIMÉNEZ ÁVILA, J., 2009: «Modelos arquitectónicos en la protohistoria suroccidental: edificios en tridente», Santuarios, oppida y ciudades: arquitectura sacra en el origen y desarrollo urbano del mediterráneo occidental, IV Simposio de Arqueología de Mérida, Mérida, 89-100.

JIMÉNEZ ÁVILA, J., 2009b: «Arquitectura y modalidad: la construcción del poder en el mundo post-orientalizante», Archivo Español de Arqueología, 82, 69-96.

JODIN, A., 1975: Recherches sur la métrologie du Maroc punique et hellénistique, Mauretania Antiqua. Études Antiques, Tánger.
JOVER MAESTRE, F. J. y SEGURA HERRERO, G., 1995: «El toro ibérico de Sax y su contexto arqueológico: el yacimiento del Chorrillo (Sax-Petrer-Elda, Alicante)», Actas del XII Congreso Nacional de Arqueología, Vol. II, Vigo, 235-240.

KAUFFMAN, E., 1974: La arquitectura de la Ilustración, Barcelona.

LLOBREGAT CONESA, E., 1972: Contestania Ibérica, Alicante.

LLOBREGAT CONESA, E., 1983: «El templo ibérico de la Illeta dels Banyets», en BLÁZQUEZ, J. M. (dir.), Religiones Prerromanas, Madrid, 489-494.

LLOBREGAT CONESA, E., 1984: «Iberización», Alcoi. Prehistoria y Arqueología. Cien años de investigación, Alcoy, 231-258.

LLOBREGAT CONESA, E., 1985: «Dos temples ibèrics a l'interior del poblat de L'Illeta dels Banyets», Fonaments, 5, 103-111.

LLOBREGAT CONESA, E., 1991: «Vías paralelas: templos y tumbas en Etruria y en Iberia», en J. REMESAL y O. MUSSO (coords.), La presencia de material etrusco en la Península Ibérica, Barcelona, 309-336.

LLOBREGAT CONESA, E., 1994: «Tradición religiosa fenicio-púnica en Contestania», El mundo púnico. Historia, Sociedad y Cultura, Murcia, 169-175.

LLOBREGAT CONESA, E., 1997: «L'Illeta dels Banyets (El Campello, Camp d'Alacant) ¿fou un empòrion?», $L a$ Illeta dels Banyets. Estudios de la Edad del Bronce y Época Ibérica, Alicante, 15-20.

LLOBREGAT, E., CORTELL, E. JUAN, J. y SEGURA, J. M., 1992: «El urbanismo ibérico de La Serreta», Recerques del Museu d'Alcoi, 1, 37-70.

LÓPEZ SEGUÍ, E., 2000: «La alfarería ibérica en Alicante. Los alfares de la Illeta dels Banyets, La Alcudia y el Tossal de Manises», Saguntum, Extra 3, 241-248.

LUCAS PELLICER, Mª. R., 1981: «Santuarios y dioses en la Baja Época Ibérica», La Baja Época de la Cultura Ibérica, Madrid, 233-293.

MALUQUER DE MOTES, J., 1981: El santuario protohistórico de Zalamea de la Serena, Badajoz. Programa de Investigaciones Protohistóricas, IV, Barcelona.

MALUQUER DE MOTES, J., 1983: El santuario protohistórico de Zalamea de la Serena, Badajoz, Programa de Investigaciones Protohistóricas, V, Barcelona.

MÁRQUEZ, C., POVEDA, A. M., SOLER, Ma . D. y TORRES, F. J., 1997: «El edificio ibérico del yacimiento de El Chorrillo (Elda-Petrer-Sax, Alicante)», Actas del XXIV Congreso Nacional de Arqueología, Vol. III, Cartagena, 327-336.

MATA PARREÑO, C., 1995: «Las influencias del mundo fenicio-púnico en los orígenes y desarrollo de la cultura ibérica», III Congrès International des Ètudes Phéniciennes et Puniques (Tunis, 1991), Vol. II, Túnez, 225-244.

MATA PARREÑO, C. y PÉREZ JORDÁ, G. (eds.), 2000: Ibers. Agricultors, artesans i comerciants. III Reunió sobre Economia en el Mòn Ibèric, en Saguntum, Extra 3.

MATALOTO, R., 2008: «O Pós-Orientalizante que nunca o foi... Uma comunidade camponesa na Herdade da 
Sapatoa (Redondo, Alentejo Central)», en J. JIMÉNEZ ÁVILA (ed.), Sidereum Ana I. El rio Guadiana en época post-orientalizante, Anejos de AEspA XLVI, 219-249.

MELGUIZO AÍSA, S., 2005: Íberos en el bajo Regallo, Zaragoza.

MONEO, T., 2003: Religio Iberica. Santuarios, ritos y divinidades (ss. VII-I a.C.), Madrid.

MORATALLA JÁVEGA, J., 2005: «El territorio meridional de la Contestania», La Contestania Ibérica, treinta años después, Alicante, 91-118.

MOREL, J.-P., 1994: «La céramique à vernis noir en Ibèrie et à Carthage: une comparaison», Íberos y griegos, lecturas desde la diversidad, Huelva Arqueológica, XIII 2, 323-344.

MORET, P., 2001-2002: «Emporion et les mutations de l'architecture ibérique au premier âge de Fer», Zephyrus, LIII-LIV, 379-391.

MORET, P., 2002: «Maisons phéniciennes, grecques et indigènes: dynamiques croisiées en Mediterranée occidentale (de l'Hérault au Segura)», Habitat et urbanisme dans le monde grec de la fin du palais mycénien à la prise de Milet (494 av. J.-C.), Pallas, 58, 329-356.

MORET, P., 2006: «Architecture indigène et modèles hellénistiques: les ambigüetés du cas ibérique», Pallas, 70, 207-227.

NIGRO, L., 2009: «Il Tempio del Kothon e il ruolo delle aree sacre nello sviluppo urbano di Mozia dall'VIII al IV sec. a.C.», en S. HELAS y D. MARZOLI (eds.), Phönizisches und punisches Städtewesen, Mainz, 241-270.

NIEMEYER, H. G., 1986: «El yacimiento fenicio de Toscanos: urbanística y función», Los fenicios en la Península Ibérica, Sabadell, 109-126.

OLCINA DOMÉNECH, M. H., 1997 (ed.): La Illeta dels Banyets (El Campello, Alicante), Estudios de la Edad del Bronce y Época Ibérica, Alicante.

OLCINA DOMÉNECH, M. H., 2005: «La Illeta dels Banyets, el Tossal de Manises y La Serreta», La Contestania Ibérica, treinta años después, Alicante, 147-177.

OLCINA DOMÉNECH, M. H., MARTÍNEZ CARMONA, A. y SALA SELLÉS, F., 2009: La Illeta dels Banyets (El Campello, Alicante). Épocas Ibérica y Romana I, MARQ Serie Mayor 7, Alicante.

OLIVER FOIX, A., 1997: «La problemática de los lugares sacros ibéricos en la historiografía arqueológica», Espacios y lugares cultuales en el mundo ibérico, Quaderns de Prehistoria i Arqueología de Castelló, 18, 495-516.

OLIVER FOIX, A., 2001: El Perengil (Vinaròs, Castellón). Un peculiar edificio ibérico, Castellón.

PENSABENE, P., 1989: «Il tempio di Saturno a Dougga e tradizioni architectonice d'origine punica», L'Africa Romana VII, Sassari, 251-293.

PONS BRUN, E., 1993: «L'expansió septentrional del món iber: el jaciment del Mas Castellar de Pontós i les seves especialitzacions», Laietània, 8, 105-128.

PONS BRUN, E., 1997: «Estructures, objectes i fets culturals en el jaciment protohistòric de Mas Castellar (Pontós, Girona)», Espacios y lugares cultuales en el mundo ibérico, Quaderns de Prehistoria i Arqueología de Castelló, 18, 71-89.
PRADOS MARTÍNEZ, F., 2004: «¿Almacenes o centros redistribuidores de carácter sacro? Una reflexión en torno a un modelo arquitectónico tipificado en la Protohistoria mediterránea», Estudios Orientales 5,6, El Mundo Púnico. Religión, Antropología y Cultura Material, Actas II Congreso Internacional de Mundo Púnico (Cartagena 2000), 173-180.

PRADOS MARTÍNEZ, F., 2005: «Memoria del Poder. Los monumentos funerarios ibéricos en el contexto de la arquitectura púnico-helenística», Cuadernos de Prehistoria y Arqueología de la Universidad Autónoma de Madrid, 28-29, 203-226.

PRADOS MARTÍNEZ, F., 2006: «Sobre arquitectura ibérica y dependencias sacras: un módulo tipificado a debate», Lucentum, XXV, 47-69.

PRADOS MARTÍNEZ, F., 2007: «La edilicia púnica y su reflejo en la arquitectura ibérica: materiales, aparejos y técnicas constructivas», Pallas, 75, 9-35.

PRADOS TORREIRA, L., 1994: «Los santuarios ibéricos. Apuntes para el desarrollo de una arqueología del culto», Trabajos de Prehistoria, 51.1, 127-140.

RAKOB, F., 1998: "Cartago. La topografía de la ciudad púnica. Nuevas investigaciones», en M. VEGAS (ed.) Cartago Fenicio-Púnica. Las excavaciones alemanas en Cartago 1975-1997, Cuadernos de Arqueología Mediterránea, 4, 15-46.

RAMALLO ASENSIO, S., 2000: «La realidad arqueológica de la 'influencia' púnica en el desarrollo de los santuarios ibéricos del sureste de la Península Ibérica», Santuarios fenicio-púnicos en Iberia y su influencia en los cultos ibéricos, XIV Jornadas de Arqueología FenicioPúnica, (Ibiza, 1999), Ibiza, 185-217.

RAMÓN TORRES, J., 2007: Excavaciones arqueológicas en el asentamiento fenicio de Sa Caleta (Ibiza), Cuadernos de Arqueología Mediterránea, 16.

RODRÍGUEZ DÍAZ, A., 2004: El edificio protohistórico de La Mata (Campanario, Badajoz) y su estudio territorial, Cáceres.

RODRÍGUEZ DÍAZ, A., 2007: «La señoralización del campo postartésica en el Guadiana Medio: el edificio protohistórico de La Mata (Campanario, Badajoz) y su territorio», Arqueología de la Tierra, paisajes rurales de la protohistoria peninsular, Badajoz, 71-102.

RUIZ DE ARBULO, J., 2000: «El papel de los santuarios en la colonización fenicia y griega en la Península Ibérica», Santuarios fenicio-púnicos en Iberia y su influencia en los cultos ibéricos, XIV Jornadas de Arqueología Fenicio-Púnica, (Ibiza, 1999), Ibiza, 9-56.

SALA SELLÉS, F., 2002: «Para una revisión de las relaciones púnicas en la costa ibérica alicantina: nuevas perspectivas sobre unos viejos problemas», Anales de Prehistoria y Arqueología. Universidad de Murcia, 1718, 283-300.

SALA SELLÉS, F., 2003: «La influencia del mundo fenicio y púnico en las sociedades autóctonas del sureste peninsular», Colonialismo e interacción cultural: el impacto feniciopúnico en las sociedades autóctonas de occidente, XVIII Jornadas de Arqueología Fenicio-Púnica, (Ibiza, 2002), Ibiza, 57-102. 
SALA SELLÉS, F., 2005: «Consideraciones en torno a la arquitectura y al urbanismo de la Contestania Ibérica», La Contestania Ibérica, treinta años después, Alicante, 119-146.

SALA SELLÉS, F., 2006: «Les fortificacions a la Contestània: entre la representació social i la defensa del territori», en A. OLIVER FOIX (coord.), Arquitectura defensiva. La protección de la población y del territorio en época ibérica, Castellón, 123-165.

SANMARTÍ GREGO, J., 2000: «Les relacions comercials en el mon ibèric, Ibers: Agricultors, artesans i comerciants», en C. MATA y G. PÉREZ (eds.), III Reunió sobre economia en el món ibèric, Saguntum, Extra 3, 307-328.

SANTACANA MESTRE, J. y BELARTE FRANCO, C., 2003: «Cabdills, estats i vi en la cruilla de la Protohistoria Ibèrica», Colonialismo e interacción cultural: el impacto feniciopúnico en las sociedades autóctonas de occidente, XVIII Jornadas de Arqueología FenicioPúnica, (Ibiza, 2002), Ibiza, 127-144.

SCHUBART, H., 1997: «El asentamiento fenicio del siglo VIII a.C. en el Morro de Mezquitilla (Algarrobo)», en
$\mathrm{M}^{\mathrm{a}}$ E. AUBET (ed.), Los Fenicios en Málaga, Málaga, 13-45.

SCHUBART, H., 2002: Toscanos y Alarcón. El asentamiento fenicio en la desembocadura del río Vélez, Cuadernos de Arqueología Mediterránea, 8.

SCHUBART, H. y MAAS LINDEMANN, G., 1984: «Toscanos. El asentamiento fenicio Occidental en la desembocadura del río Vélez. Excavaciones de 1971», Noticiario Arqueológico Hispano, 18, 39-210.

TUSA, V., 2000: «Il santuario fenicio-punico di Mozia, detto di Cappidazzu», IV Congreso Internacional de Estudios Fenicios y Púnicos, Vol. III, Cádiz, 1397-1418.

VILÀ PÉREZ, C., 1997: «Arquitectura templal ibérica», Quaderns de Prehistoria i Arqueología de Castelló, 18, 537-566.

VISEDO MOLTÓ, C., 1922: Excavaciones en el monte La Serreta, próximo a Alcoy, Memorias de la Junta Superior de Excavaciones Arqueológicas, 41, Madrid

WOOLEY, L., 1938: «Excavation at Al-Mina, Sueia», Journal of Hellenistic Studies, 58, 1-30. 